University of Louisville

ThinkIR: The University of Louisville's Institutional Repository

Electronic Theses and Dissertations

8-2015

\title{
The regulation and mechanisms of EGFR-mediated apoptosis in MDA-MB-468 cells.
}

Nicole Marion Jackson

University of Louisville

Follow this and additional works at: https://ir.library.louisville.edu/etd

Part of the Pharmacy and Pharmaceutical Sciences Commons

\section{Recommended Citation}

Jackson, Nicole Marion, "The regulation and mechanisms of EGFR-mediated apoptosis in MDA-MB-468 cells." (2015). Electronic Theses and Dissertations. Paper 2216.

https://doi.org/10.18297/etd/2216

This Master's Thesis is brought to you for free and open access by ThinkIR: The University of Louisville's Institutional Repository. It has been accepted for inclusion in Electronic Theses and Dissertations by an authorized administrator of ThinkIR: The University of Louisville's Institutional Repository. This title appears here courtesy of the author, who has retained all other copyrights. For more information, please contact thinkir@louisville.edu. 


\title{
THE REGULATION AND MECHANISMS OF EGFR-MEDIATED APOPTOSIS
} IN MDA-MB-468 CELLS

\author{
By \\ Nicole Marion Jackson \\ B.A., Cheyney University of Pennsylvania, 2012
}

\begin{abstract}
A Thesis
Submitted to the Faculty of the School of Medicine of the University of Louisville In Partial Fulfillment of the Requirements for the Degree of

Master of Science in Pharmacology and Toxicology

Department of Pharmacology and Toxicology University of Louisville

Louisville, Kentucky
\end{abstract}

August 2015 



\title{
THE REGULATION AND MECHANISMS OF EGFR-MEDIATED APOPTOSIS
} IN MDA-MB-468 CELLS

\author{
By \\ Nicole Marion Jackson \\ B.A., Cheyney University of Pennsylvania, 2012 \\ Thesis Approved on
}

July 21,2015

By the following Thesis Committee:

Brian P. Ceresa, Ph.D.

Paula J. Bates, Ph.D.

Levi J. Beverly, Ph.D.

Geoffrey J. Clark, Ph.D.

Leah J. Siskind, Ph.D. 


\section{DEDICATION}

This thesis is dedicated to my family.

Without their love, encouragement and optimism, I could not prosper. 


\section{ACKNOWLEDGMENTS}

I would like to acknowledge and thank my mentor, Dr. Brian P. Ceresa. He has been and continues to be supportive, encouraging, and patient with both my scientific endeavors and with me. I would also like to thank all of the Ceresa lab members, and my committee members for their guidance and feedback with this project. 


\section{ABSTRACT \\ THE REGULATION AND MECHANISMS OF EGFR-MEDIATED APOPTOSIS IN MDA-MB-468 CELLS}

Nicole Marion Jackson

July 21,2015

Background: The Epidermal Growth Factor Receptor (EGFR) is a 170kilodalton transmembrane protein that belongs to the ErbB family of receptor tyrosine kinases. Upon ligand-mediated activation, the EGFR responsible for cell growth, proliferation, and tissue homeostasis in epithelial cells; however, the EGFR is overexpressed in many human malignancies including MDA-MB-468 cells, a metastatic breast epithelial cell line. Previous studies have indicated that within the MDA-MB-468 cell line, receptors at the cell surface promote cell growth when activated with Epidermal Growth Factor (EGF) ligand. Activated receptors that are internalized to the endosomes however induce apoptosis. This contrasting response at different cellular locations is defined as spatial regulation. The overarching research goal of this thesis is to better understand the spatial regulation within these cells, and identify the effector proteins responsible for the difference in signals emanated at the cell membrane versus intracellularly. The goals of this thesis were to first determine whether other EGFR ligands, Betacellulin (BTC) and Transforming Growth Factor-alpha (TGFA), are able to induce apoptosis in the MDA-MB-468 cell line. The second goal was to identify 
effectors downstream of EGFR activation that could have potential implications in EGFR-mediated apoptosis. Methods: An MTT assay was conducted in order to evaluate the viability of the MDA-MB-468 cells after treatment and activation with 3 EGFR ligands: EGF, BTC, or TGFA. EGF activity was measured as a function of receptor phosphorylation. Western blot analysis was conducted after MDAMB-468 cell exposure to increasing concentrations of the three ligands. This was done in order to identify any variances or similarities in phosphorylation patterns amongst the three ligands. Lastly, cell morphology was observed after the cells were exposed to $16 \mathrm{nM}$ concentrations of each ligand for 24 hours. A different approach to assessing EGFR spatial regulation was then employed. MDA-MB468 cells were subjected to time course and dose response experiments, prior to the ultimate assessment of various different effectors. Results: All ligands induced dose dependent decreases in cell viability. All three ligands signaled through the EGFR, as measured by receptor phosphorylation, with similar phosphorylation patterns. Western blot analyses indicate a dose dependent increase in EGFR phosphorylation in response to all ligands. MDA-MB-468 cells were round in morphology at 24-hour time points with exposure to high concentrations of all ligands. An effector screening was conducted, which resulted in the discovery of upregulated STAT3 activity, preferentially with high EGF concentrations. This suggests the potential for STAT3 to mediate apoptosis, and be spatially regulated in MDA-MB0468 cells. After confirming the upregulation of STAT3 in an EGFR dependent manner, commercially available inhibitors of STAT3 were employed; however the inhibitors exhibited non-specific 
effects, in vitro. Conclusions: These data suggest that EGFR signaling in MDAMB-468 cells is not ligand specific, and that activation and internalization of the receptor in this cell line with any endogenous ligand will result in cell death. The results indicate a potential role of STAT3 in EGFR-induced apoptosis. Future experiments will entail employing siRNA targeting STAT3 in order to determine the role of STAT3 in EGFR-induced apoptosis. 
TABLE OF CONTENTS

PAGE

DEDICATION ..................................................................... ii

ACKNOWLEDGEMENTS ...................................................... iv

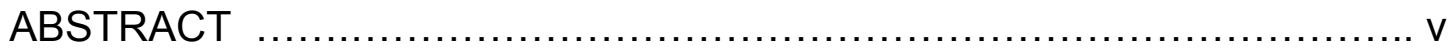

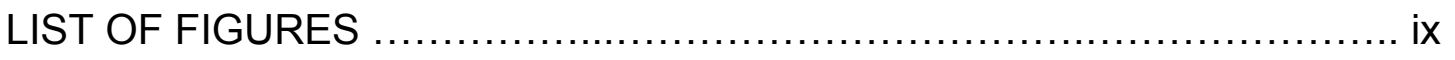

BACKGROUND AND INTRODUCTION .................................... 1

CELL DEATH AND APOPTOSIS ........................................... 12

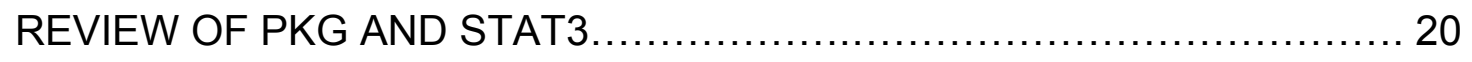

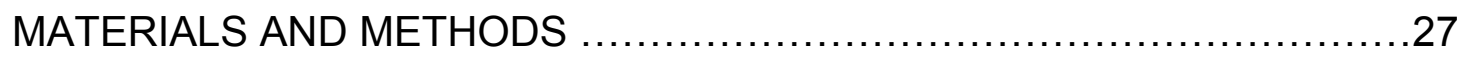

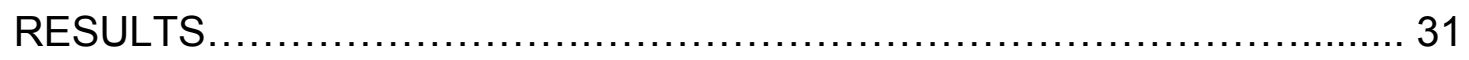

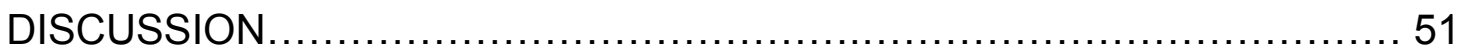

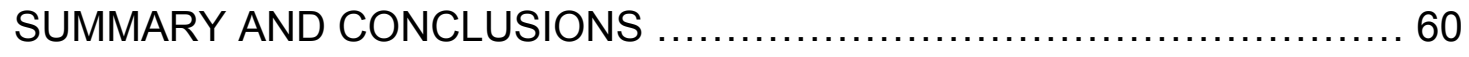

STRENGTH AND LIMITATIONS ................................... 61

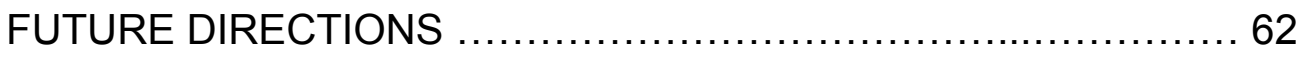

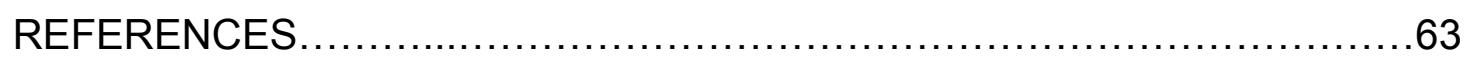

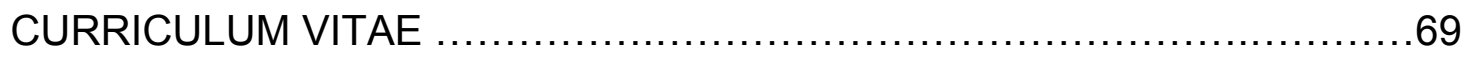




\section{LIST OF FIGURES}

PAGE

1. Figure 1. The amino acid sequence of EGF ligand ................... 3

2. Figure 2. Schematic representation of apoptotic events..............15

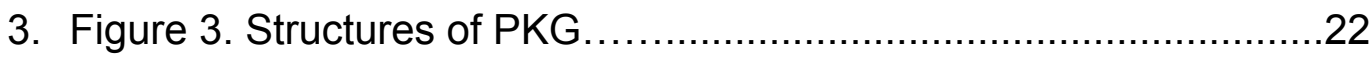

4. Figure 4. EGF, BTC, and TGFA ligands induce dose dependent decreases in cell viability in MDA-MB-468 cell line.....................33

5. Figure 5. EGF, BTC, and TGFA ligands each induce a rounded cellular morphology in MDA-MB-468 cells ................................34

6. Figure 6. EGF, BTC, and TGFA induce dose dependent increases in EGFR phosphorylation .35

7. Figure 7. Identifying differences in EGFR-effector signaling between low $(1 \mathrm{ng} / \mathrm{mL})$ and high (100 $\mathrm{ng} / \mathrm{mL})$ EGF ligand exposures.

8. Figure 8. MAPK, SRC, AKT, and BAD exhibit no significant differences in EGFR signaling at low versus high ligand concentrations

9. Figure 9. Increases in EGF ligand concentration elicit a dose dependent increase in p-VASP(SER239) phosphorylation

10. Figure 10. Dose dependent increase in PKG activator, 8-BromocGMP, induces a dose dependent decrease in cell viability 


\section{LIST OF FIGURES}

PAGE

11. Figure 11. The use of PKG agonist, 8-Bromo-cGMP, confirms that PKG does not elicit EGFR phosphorylation. .44

12. Figure 12. pSTAT3(Tyr705) is upregulated in both a dose and time dependent manner, at high EGF ligand concentrations 45

13. Figure 13. Commercially available STAT3 antagonists exhibit nonspecific inhibition of STAT3 in MDA-MB-468 cells 47

14. Figure 14. STATTIC induces a dose dependent decrease in cell viability .48

15. Figure 15. siRNA targeting STAT3 are able to significantly reduce STAT3 activity .50

16. Figure 16. Working model for how EGFR-induced apoptosis occurs in a PKG-mediated manner. 55

17. Figure 17.Two models describing the potential roles of STAT3 in EGFR-induced apoptosis in MDA-MB-468 cells 59 


\section{BACKGROUND AND INTRODUCTION}

The epidermal growth factor receptor (EGFR) is a cell surface receptor that is expressed in almost every tissue of the body and plays critical roles in development and tissue homeostasis. Further, many cancers are characterized by hyper-activated EGFR signaling, either due to overexpression of the receptor or somatic activating mutations of the receptor. These perturbations in EGFR expression and/or activation are associated with poor patient prognosis. Over the last 15-20 years, there has been a concerted effort to develop cancer therapeutics that specifically target the aberrant EGFRs, with the goal of inhibiting the progression of those cancers. Understanding the basic cell biology of the EGFR helps to understand its implications, and define its typical role in normal cell biology.

In order to better understand the function of the EGFR, it is best to start with the discovery of one of the principal ligands that initiates its activity. Dr. Stanely Cohen isolated and discovered its endogenous ligand, Epidermal Growth Factor (EGF) from murine submaxillary glands in the early 1960's. Frozen submaxillary glands were obtained from mice and homogenized in acetic acid, prior to being frozen in a dry ice-alcohol bath. The material was then thawed and subjected to a series of ultra-centrifugations at $100,000 \times \mathrm{g}$, and acetic acid 
washes. The newly formed pellet was then subjected to size exclusion, and ion exchange chromatography for purification [1]. Amino acid analysis of the purified product revealed that EGF is a 53 amino acid residue polypeptide, containing three internal disulfide bonds, as depicted in Figure 1.

Dr. Cohen observed that injecting the purified, crude, submaxillary gland preparations into newborn mice stimulated growth of embryonic neurons and induced precocious eyelid opening. Having identified a growth factor that was able to initiate some very specific physiological responses, the next goal was to identify the receptor. In 1978, he and Dr. Graham Carpenter were able to identify the presence of the 170 kilodalton EGFR specific for EGF ligand through the use of radiolabeled ( ${ }^{125}$ I-labeled) EGF ligand in A-431 cells, a human epidermoid carcinoma cell line. They reported increased ${ }^{32} \mathrm{P}$ incorporation in the A-431 cells in response to EGF ligand stimulation, suggesting that phosphorylation of EGFR components might be critical for its function [2]. In 1982, Dr. Cohen proceeded to then successfully isolate and purify the EGFR from A-431 cells, and from normal mouse liver cells by means of affinity chromatography. Purification of the receptor aided in the confirmation that the EGFR was able to bind ${ }^{125}$ I-labeled EGF, and that the receptor possessed ligand stimulated, intrinsic kinase activity, which was responsible for auto-phosphorylation of tyrosine residues, upon binding of EGF. This particular study also confirmed that the receptor in normal liver cells had biochemical similarities to receptors found in the carcinoma cell line [3]. The contributions of Dr. Cohen and Dr. Carpenter have allowed for 


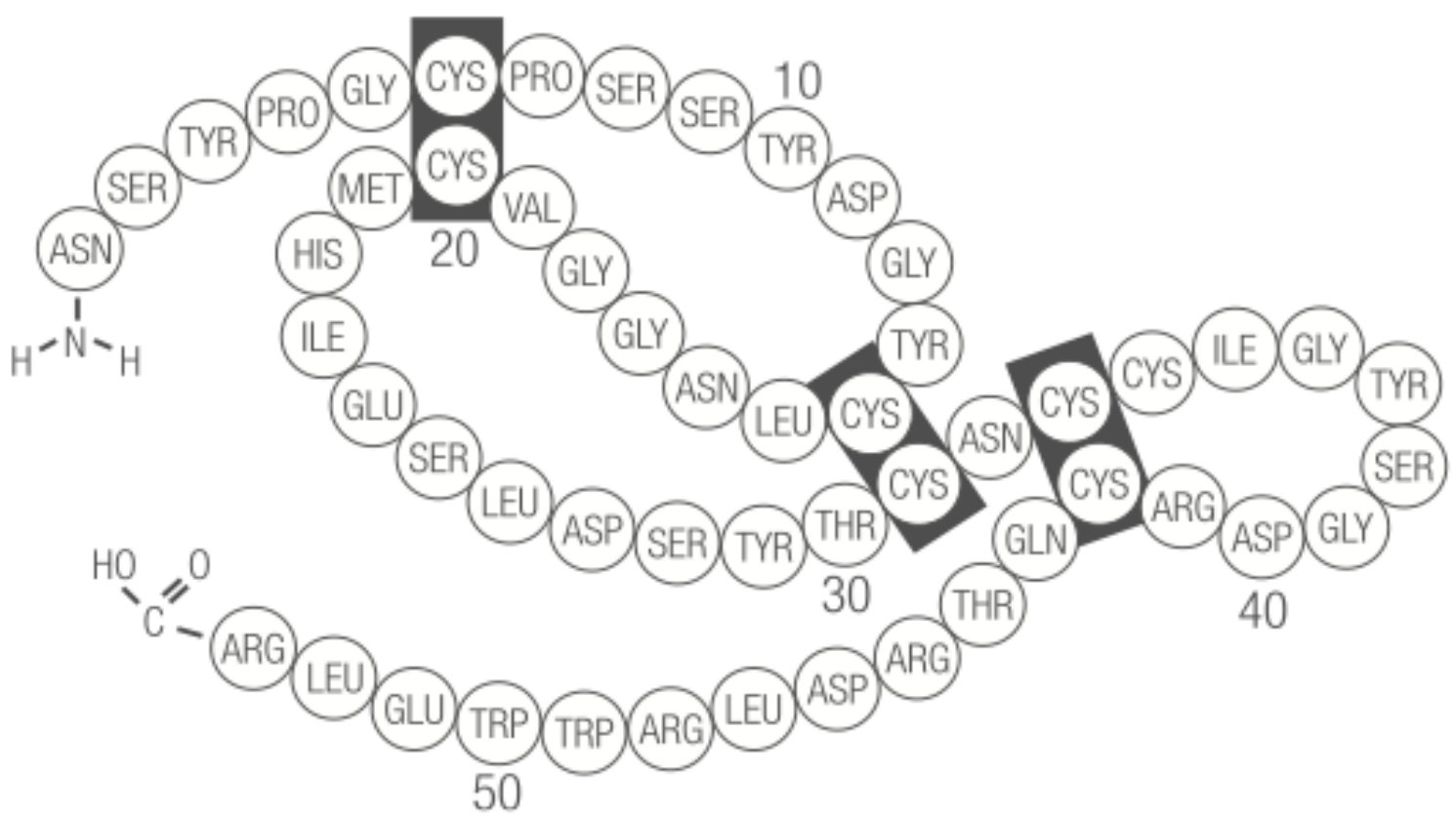

Figure 1. The amino acid sequence of EGF ligand, isolated and purified from murine submaxillary glands. (from Journal of Biological Chemistry (1973) 248, 7669-7672) 
subsequent studies to unveil further information about the receptor, including its physiology, function, and regulation.

Another huge leap in our understanding of the molecular mechanism of EGFR-mediated signaling came in 1984 when Ullrich and colleagues used the newly identified tools of molecular biology to clone the human EGFR. From this report, a model (which has been modified numerous times over the years) was generated that described the functional domains of the EGFR.

The EGFR is comprised of three major domains: 1) an extracellular, ligand binding domain with cysteine rich regions, 2) a cytosolic, intrinsic kinase domain, and 3) a cytosolic domain containing tyrosine residues [4]. Studies by Lax et al. devised a method utilizing ${ }^{125}$ I-labeled EGF to label the EGFR for subsequent isolation, and cleavage through use of Cyanogen Bromide (CNBr). Site-specific antibodies were then used to identify certain residues (293 and 543) that are critical for the function of the receptor. On the basis of amino acid sequence conservation, it was then determined that the extracellular domain was comprised of 600 amino acids, and could be divided into 4 sub-domains [5]. Domains I and III are ligand binding regions, with $37 \%$ homology that physically bind the ligand. Domains II and IV are rich in cysteine, and have $17 \%$ amino acid homology that interfaces with other receptors for dimerization [6, 7].

The model of how these domains come together is based on crystallographic analysis that was done by the Lemmon laboratory. In the unliganded state, the cysteine-rich domains of a monomeric receptor bind to one another through an intramolecular interaction. Upon the introduction of ligand, 
the receptor undergoes a conformational change such that both ligand binding domains bind the ligand and disrupt the interaction between the two cysteine rich domains. The exposure of cysteine rich domain I then can interact with the corresponding domain with another EGFR to form a dimer. Ligand binding also brings about a conformational change that activates the intrinsic kinase domain, which then leads to autotransphosphorylation of the cytosolic tyrosine residues [8]. The kinase domain of each receptor moiety will phosphorylate tyrosine residues on its adjacent dimer partner by a conformational change in the receptor that places the tyrosine substrate in access to the kinase domain. These phosphotyrosines then serve as docking sites for various cytoplasmic enzymes, known as effector molecules. By docking to the phosphotyrosines, these effectors become activated and modulate various cellular processes that contribute to the overall cell biology [9]. For example, activation of the EGFR by EGF leads to activation of the Janus Kinase (JAK) tyrosine kinase in the cytosol. The JAK protein then proceeds to phosphorylate and activate the signal transducers and activators of transcription (STAT) proteins [10]. This JAK/STAT signaling cascade is a pathway implicated in cell survival responses [11]. Activation of alternative downstream signaling cascades by the EGFR induces known responses for cellular differentiation, proliferation, migration, and protection from apoptosis [12].

Although the EGFR is expressed at the cell surface of many normal cells, and is critical for animal development and cellular homeostasis, it is often mutated and/or hyper-expressed in a number of human malignancies [13]. In a 
study conducted by Real et al., mouse monoclonal antibodies specific for the EGFR were used to assess the distribution of the receptor in various human cell and tissue types. These studies have confirmed EGFR expression in normal stomach, bladder, colon, esophageal, and lung tissue; however, no expression was determined in normal brain tissue or skeletal muscle [14]. In regard to malignant cells and tissue, the EGFR has shown to be hyper-expressed in colon, kidney, lung and sarcoma cancers; however, it is non-prevalent in primary melanoma [14] and gliosarcoma malignancies [15].

In the analysis of large populations of cancers with EGFR mutations, one of the most common mutations entails a deletion of exons 2-7 of the EGFR gene that removes virtually the entire extracellular domain of the receptor. In the absence of a ligand binding domain or cysteine rich domains that have intramolecular binding that prevents dimerization, this receptor is free to associate with other mutant receptors and is constitutively active. This mutant receptor is referred to as EGFRvIII, and is substantially expressed in patients with glioblastoma malignancies $[16,17]$. Mutated tyrosine residues of the EGFR at the cytosol have also been shown to induce aberrant signaling as well as drug resistance in cancers characterized by hyper-expression of the EGFR $[18,19]$. In addition to the EGFR itself, studies have shown that alterations in EGFR ligand expression can hinder certain tissue physiology. Luetteke et al. bred knockout mice that lacked endogenous expression of various, endogenous EGFR ligands. Pups born to these knockout mice were runted, and showed stunted growth and survival. These data provide confirmation of a requirement for EGFR ligands to 
initiate receptor signaling in order for proper development of the mouse mammary gland [20]. Overall, it can be inferred that regulation of tyrosine phosphorylation as well as endogenous EGFR ligands are both critical for proper signaling and modulation of cellular effects of the activated receptor.

Numerous cellular processes play a role in controlling EGFR activity. Chief among these is ligand-mediated endocytosis. Co-incident with ligand binding to the EGFR and activation of the intrinsic kinase domain, the ligand:receptor complex is internalized into the cell in either a clathrin-mediated, or clathrinindependent manner. Clathrin-coated vesicles were first identified in osteocytes [21], and then later in neurons [22]. In 1975, Barbara Pearse biochemically characterized these clathrin-coated vesicles as transport vesicles upon isolating and purifying them from pig brains prior and analyzing their physical properties via electron microscopy. She described these vesicles as intracellular vesicles with unique "coats" on their cytoplasmic surfaces [23]. Her discovery serves as the foundation of biochemical studies entailing clathrin-mediated endocytosis and membrane trafficking in general.

Sigismund et al. stimulated receptor activation with EGF for 2 minutes in HeLa cells prior to immunostaining and subjecting the fixed cells to immunoelectron microscopy. Immunoelectron microscopy allowed for viewing and imaging of the immunostained cells in their various compartments during EGFR mediated endocytosis [24]. These studies, as well as subsequent studies, revealed that Clathrin-mediated EGFR endocytosis is observed at all ligand 
concentrations, where as with higher concentrations of ligand, $(10-100 \mathrm{ng} / \mathrm{mL})$ the receptor undergoes Clathrin-independent endocytosis via caveolae $[25,26]$.

Once internalized within the cell, the EGFR is subjected to the endocytic pathway, a pathway responsible for sorting and determining the ultimate fate of the internalized ligand:receptor complex. An intermediate vesicle containing the ligand:receptor complex fuses with an early endosome. The mildly acidic environment of the early endosome $(\mathrm{pH} 6)$ allows for certain EGFR ligands (EGF and transforming growth factor-alpha (TGFA)) to dissociate from the EGFR, should the ultimate fate of the receptor be recycling back to the plasma membrane [27]. From here, the unbound-receptor will recycle back to the cell membrane via recycling endosomes for additional ligand binding and signaling. These recycling endosomes, slightly acidic at $\mathrm{pH} 6.4$, are generally located within the cell, and are centered around the microtubule-organizing center [28]. These recycling endosomes exhibit tubular-vesicular morphology, which suggests dynamic trafficking activity and supports their involvement with the underlying connection of endocytosis with exocytosis [29, 30]. Should the ligand:receptor complex remain inside of the early endosome, however, the early endosome will mature into a late endosome with the complex intact. The late endosome then fuses with the lysosome just prior to the ultimate degradation of the ligand:receptor complex [31]. This endocytic pathway is essential for regulating the activity of the EGFR, both temporally and spatially. Temporally, meaning that the time it takes the receptor to transverse the entire endocytic pathway will ultimately dictate the duration of its signaling. Spatially, in regard to the fact that 
at different subcellular locations, the receptor will interact with different effector proteins, activating different signaling cascades [32].

Due to hyper-expression of the EGFR in a number of human malignancies, including kidney, breast, pancreatic, and cervical cancers [33], the correlation between signaling by the EGFR and the endocytic pathway has important implications in both receptor tyrosine kinase and cancer biology [32]. One approach utilized to assess this correlation involves studying EGFR signaling and endocytosis upon activation with different ligands. Currently, there are seven identified growth factor proteins that are able to bind to and activate the EGFR: these include EGF, amphiregulin (AREG), betacellulin (BTC), epigen (EPGN), epiregulin (EREG), heparin-binding EGF-like growth factor (HBEGF), and TGFA [34]. Although each of these ligands stimulates EGFR activation and internalization, they yield diverse effects on endocytic sorting [35]. This information can be used advantageously to assess the differential effects and regulatory mechanisms different ligands have on EGFR signaling. One of the critical components of this thesis entails determining if EGFR ligands have differential effects on EGFR-mediated apoptosis.

EGF is a 53 amino acid, 6.4 kilodalton $(\mathrm{kDa})$ protein that has been shown to be involved in regulation of cellular proliferation in mammals $[36,37]$. Similarly to EGF, TGFA ligand contains 50 amino acids and has a molecular weight of approximately $6 \mathrm{kDa}$. Both EGF and TGFA bind the EGFR; however, TGFA binds with $10-30$ fold less affinity to the receptor in rat hepatocytes in comparison to EGF. Thoresen et al. isolated hepatocytes from Wistar rats prior to stimulating 
the cells with increasing concentrations of ${ }^{125}$ I-EGF and ${ }^{125}$ I-TGFA. Surface binding curves after 24-hour ligand exposure exhibit a binding affinity of $11.9 \mathrm{nM}$ for TGFA, and $0.42 \mathrm{nM}$ for EGF. The data within this study suggest that the two ligands compete for a single population of binding sites in rat hepatocytes, although EGF has a significantly higher binding affinity for the EGFR than TGFA [38]. It is important to note that TGFA is synthesized and most prevalent in cancer cells, and cells transformed by oncogenes and retroviruses [39]. BTC, a slightly larger ligand ( $9 \mathrm{kDa}$ ) comprised of 80 amino acids, was originally isolated from mouse insulinoma cells, and is able to activate EGFR and ErbB4 [40]. Studies utilizing ${ }^{125}$ I-BTC in Balb/c 3 T3 fibroblasts confirm a binding affinity of $0.5 \mathrm{nM}$ for the EGFR, and suggest that the preferred receptor for BTC is the EGFR [41].

All three of these ligands are able to bind to the EGFR, and stimulate kinase activity; however, they differ in regard to their binding affinities to the EGFR, and their ultimate fates upon endocytosis and endocytic trafficking. In order to compare ligand internalization upon EGFR stimulation, Roepstorff et al. used an approach of pre-binding various EGFR ligands on ice to view the synchronized wave of receptor internalization. After determining optimal incubation time using ${ }^{125}$ I-EGF, HEp2 cells were incubated with increasing ligand concentrations for 100 minutes. The amount of total cell surface receptors was then determined by means of FACS analysis. These data show that EGF and BTC ligands both target the EGFR for lysosomal degradation. In contrast, TGFA almost always leads to recycling of the EGFR to the cell membrane within 90 
minutes of ligand exposure [35]. EGF and BTC can both withstand the acidic conditions of the endosomes, dissociating at around $\mathrm{pH}$ 5. In contrast, TGFA rapidly dissociates from the receptor at $\mathrm{pH} 7$, and is unable to withstand the acidic environment of the early endosome. This therefore causes the ligand-free receptor to recycle back to the cell membrane [35, 42]. The fate of the EGFR, whether it is for degradation or recycling, is critical for its duration of signaling, which will vary based on different ligands bound to the receptor. This has ultimate implications in the initiation different signaling cascades.

In summary, the EGFR is a transmembrane receptor tyrosine kinase with critical implications in normal cell growth, proliferation, wound healing, and tissue homeostasis. It is regulated in both a spatial and a temporal manner. Trafficking of the receptor can vary depending on the ligand it is bound to. The EGFR is however hyperexpressed in mammalian cancer [33]. There is more known about EGFR cell biology in non-malignant tissue, more so than in cancer cells. Research has shown that pharmaceutically available EGFR inhibitors provided to cancer patients triggers autophagy, a degradative process that actually helps cancer cells withstand nutrient-poor conditions [43]. The primary focus of this thesis is to better understand the function and role of the EGFR in cell growth and apoptosis in cancer. Doing so will require determining if different ligands have varying effects on cell viability and apoptosis. It is also of interest to identify specific proteins with direct implications in EGFR-induced apoptosis. This will help to develop better, more efficacious therapy for cancers that hyperexpress the receptor. 


\section{CELL DEATH AND APOPTOSIS}

The EGFR is typically associated with cell growth, development and tissue homeostasis; however, it has been also known to mediate cell death in cancers that hyperexpress EGFRs [44-46]. Using a cell line that undergoes EGFRmediated apoptosis uniquely allows for the enlightenment of the biochemical regulation of signaling by using a sensitive, tractable and irreversible readout. These findings can be used to better understand other signaling pathways and biological responses to cell growth, and its counterpart, programmed cell death.

The term apoptosis entails the process of programmed cellular death in both single-cellular and multicellular organisms. Programmed cell death refers to the time and position of cell death during development of a given organism. It has many functions during the development process, including adjusting and deleting cell numbers [47]. Both apoptosis and programmed cell death are normal processes in growth, development and aging as a homeostatic mechanism for proper maintenance of cell populations in tissues [48]. John Kerr first used the term apoptosis in 1972, in order to describe a morphologically distinct form of cell death. Through the use of light and electron microscopy, morphological events that occur during apoptosis have been identified [49]. The process of apoptosis entails structural changes that take place in two distinct stages: During stage one, the cell rounds in shape, shrinks, and breaks into well-preserved fragments. 
Its nuclear and cytoplasmic compartments condense, causing the cellular organelles to become more tightly packed as well as fragmented $[48,50]$. Pyknosis, or chromatin condensation, is a key characteristic component of apoptosis [48]. During the second stage, the apoptotic body, a small sealed membrane that is released by cells undergoing programmed cell death [51], is taken up by other cells just prior to being degraded and broken down within the lysosome [50]. This helps to remove any superfluous material, and provide nutrients that were once in the apoptotic cell to the cell that is viable [52]. The apoptotic process is a critical component in normal human embryonic development, and tissue homeostasis in all living organisms [48, 53]. However, cancer cells often have the ability to avoid apoptosis, and continue to proliferate [54]. This dysregulation of apoptosis is associated with many malignancies, including breast, ovarian and colon cancers $[55,56]$. Consequently, this can lead to cellular accumulation within a given organism, creating a permissive environment for genetic instability and oncogene activation. These events are known to disrupt cell turnover and function, as well as damage and kill healthy, viable cells [57].

Alternatively to apoptosis, cell death can also occur in a necrotic manner. Necrosis is considered to be a degradative, toxic process that consequently induces cell swelling [58,59], opposite of apoptosis [58]. Necrosis is an uncontrolled process and requires no energy input. It typically affects a large population of cells, and causes inflammation, in vivo. Conversely, apoptosis is a controlled and energy-dependent process that does not induce inflammation, and 
can occur in individual cells as well as large clusters of cells [48]. The manner of cell death by either necrosis or apoptosis depends on the nature of the tissue type, its developmental stage, and the cell death signal itself [60].

There are several biochemical modifications of apoptotic cells, which can be used to help differentiate and identify them. Such modifications include DNA breakdown, phagocytic recognition, and protein cleavage and cross-linking [61]. The caspase proteins are a family of aspartic acid-specific proteases that have proteolytic activity and are major effectors of apoptosis $[48,62]$. They are normally synthesized as inactive precursors, or pro-enzymes, and only become activated upon the induction of apoptosis. The pro-enzymatic form gets cleaved and activated by other caspases, initiating a signaling cascade as well as apoptosis induction [62]. Currently, there are 14 caspases that have been identified [63]. These are categorized into three subgroups based on their function within the signaling cascade. Initiator capsases (caspases 2, 8, 9, and 10) begin the cascade by activating and cleaving the executioner caspases (caspases 3, 6, and 7) at aspartic acid residues. Once executioner caspases are activated, they cleave and activate other cellular substrates, such as poly (ADPribose) polymerase (PARP), ultimately starting the apoptotic process [48, 64]. The third subgroup of caspase proteins includes caspases 1, 4 and 5, which have more active roles in cytokine maturation [65].

Mechanistically, apoptosis is quite complex, involving two main pathways: the extrinsic and intrinsic pathways (Figure 2). The extrinsic signaling pathway 


\section{Extrinsic Pathway}

\section{Intrinsic Pathway}

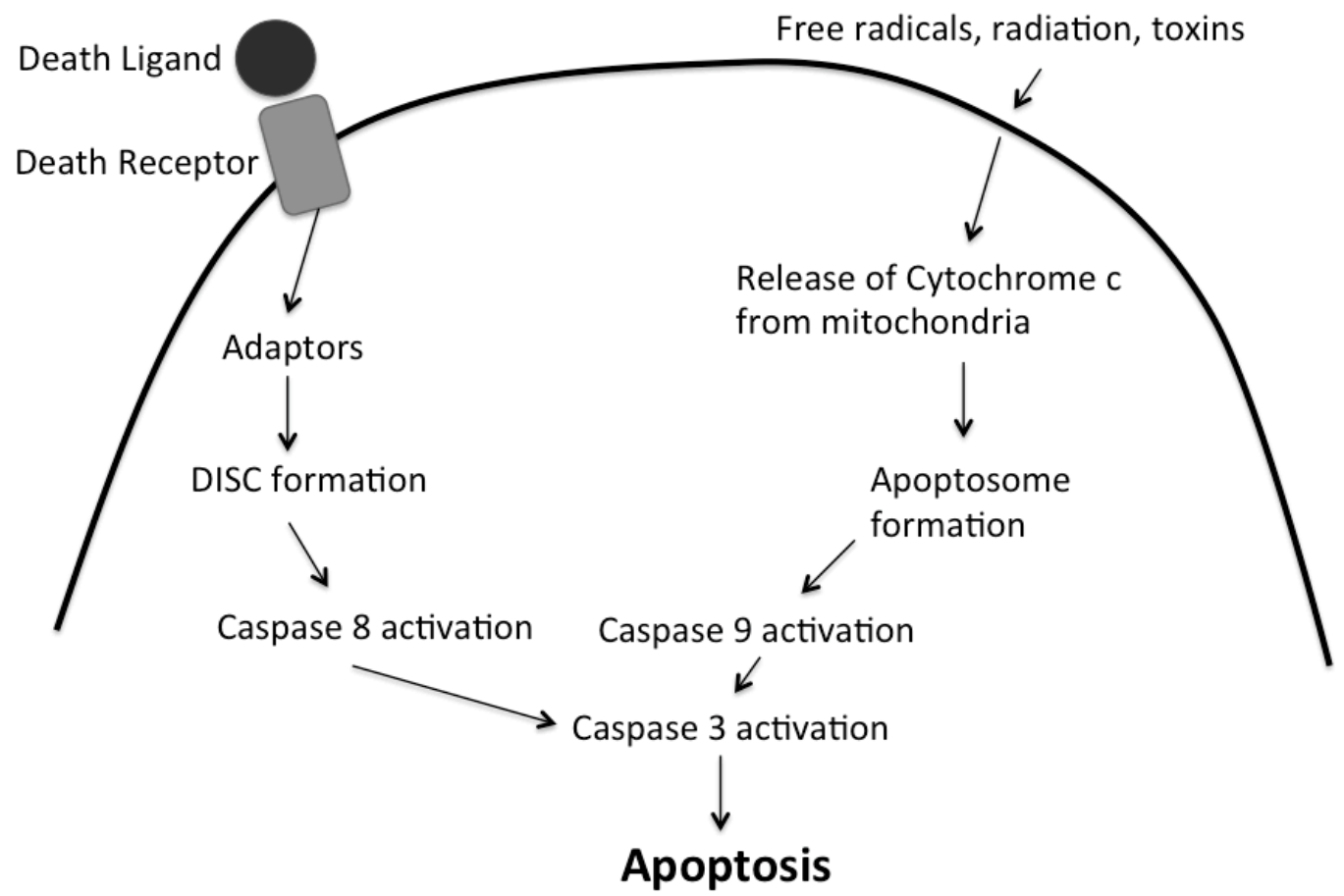

Figure 2. Schematic representation of apoptotic events. (Adapted from Elmore et al., Toxicol Pathol., 2007) 
entails initiating apoptosis via transmembrane receptor-mediated interactions. These receptors are known as "death receptors", and are members of the tumor necrosis factor (TNF) receptor family [66]. Members of this family have a "death domain", which is a cytoplasmic domain comprised of 80 amino acids.

The death domain of TNF receptors is primarily responsible for relaying signals for cell death from the cell membrane to the intracellular signaling pathways $[48,67]$. Upon ligand binding, adapter proteins are recruited to the death receptors at corresponding death domains. For instance, Fas ligand, a ligand with a known biological function of inducing apoptosis [68], binds to the Fas receptor, a member of the TNF receptor family. This ligand-receptor interaction promotes the intracellular recruitment of the FADD adapter protein [69]. FADD then associates with procaspase-8, forming a death-inducing signaling complex (DISC). This then results in the auto-catalytic activation of caspase-8 from procaspase-8 [70]. The activated caspase-8 then activates executioner caspases, which leads to the induction of apoptosis. Defects in Fas ligand and Fas receptor are causes of various autoimmune diseases. It has been shown that upon knocking out the fas gene by homologous recombination, generalized lymphoproliferative disease (gld) can be completely recapitulated in mouse models [71]. Similarly, gld can be completely cured by simply expressing the normal fas gene in the same knockout mice [72]. These studies exhibit how critical Fas-induced apoptosis is to the regulation and cellular homeostasis of immunocompromised organisms. 
The intrinsic signaling pathway of apoptosis initiates apoptosis in a nonreceptor mediated manner. This pathway entails mitochondrial- initiated events, involving certain stimuli that send intracellular signals to act on specific targets within the cell. These intercellular signals can be positive or negative signals. Negative signals often lead to withdrawal of certain growth factors, which fails to suppress death processes and essentially triggers apoptosis. On the other hand, positive signals include those for free radicals, toxins, and viral infections [48]. Apoptotic signals originating from the cell surface lead to the release of cytochrome $\mathrm{c}$ from the mitochondria into the cytosol, where it ultimately binds to the Apoptotic Protease Activation Factor-1 (Apaf-1). The binding of cytochrome c to Apaf-1 initiates apoptosome formation, which catalyzes the activation of caspase $9[48,73]$. Identical to the extrinsic pathway of apoptosis, activation of caspase 3 then leads to the downstream induction of apoptosis.

Although the EGFR is typically associated with cell growth and proliferation, forms of cancer that hyper-express the receptor often undergo EGFR-mediated apoptosis. MDA-MB-468 cells are a metastatic breast epithelial cell line, derived from the M.D. Anderson Cancer Center in Houston, Texas [74]. In this cell line, the EGFR is hyper-expressed, with approximately $1.3 \times 10^{6}$ receptors per cell [75]. Initial studies with this cell line revealed that lower than physiological levels of EGF ligand (1 $\mathrm{ng} / \mathrm{mL})$ enhance cell growth; however, ligand concentrations that exceed $10 \mathrm{ng} / \mathrm{mL}$ induce dose dependent decreases in cell viability [44] . Studies within the Ceresa laboratory utilizing MDA-MB-468 cells have shown that when activated and retained at the cell membrane, the 
EGFR elicits signals for cell growth; however, once internalized within the endosomes, the receptor elicits signals for apoptosis. Polystyrene beads of 0.9micrometer size covalently conjugated to EGF ligand were used for this determination. The polystyrene bead itself is too large for clathrin-mediated internalization. The conjugated EGF is able to activate the receptor while the bead retains the activated receptor to the cell membrane. Cells treated with EGF beads did not activate Caspase 3, where as cells treated with soluble EGF did activate Caspase 3.

Immunoblot analyses from the Ceresa laboratory have disclosed that there is a defect in endocytic trafficking within this cell line [76]. Through use of Percoll gradient and indirect immunofluorescence assays, Rush et al. have shown that instead of traversing the entire endocytic pathway to the lysosome for degradation, the EGFR accumulates on the limiting membrane of the early endosome in MDA-MB-468 cells. In the same study, HeLa cells, which express physiological levels of EGFR and do not undergo EGF-induced apoptosis, were treated with Monensin in order to block the acidification of the early endosome. This essentially stopped trafficking of the EGFR beyond the endosome, causing EGFRs to accumulate in the early endosome, mimicking the same defect found in the MDA-MB-468 cell line. Treatment with Monensin and EGF ligand in HeLa cells caused the cells to undergo EGFR-mediated apoptosis [77].

In summary, apoptosis and programmed cellular death are normal processes within the lifespan of the cell. There are key physiological and 
morphological features that distinguish apoptotic cells from necrotic and viable cells. The EGFR is implicated in apoptosis in cell lines that hyperexpress it. Data from the Ceresa laboratory indicate that in addition to undergoing EGFRmediated apoptosis, this apoptotic process is spatially regulated within MDA-MB468 cells. Progression within this project involves determining all of the necessary protein components implicated in EGFR-mediated apoptosis. 


\section{REVIEW OF PKG AND STAT3}

There are two major goals of this project: the first being to determine whether or not various EGFR ligands induce differential outcomes on viability and apoptosis. The second goal was to identify proteins suspected of having direct implications in the EGFR-induced apoptotic process in the MDA-MB-468 cell line. As previously mentioned, it has been shown that low $(<10 \mathrm{ng} / \mathrm{mL})$ concentrations of EGF ligand enhance cell growth within this cell line. Ligand concentrations that exceed $10 \mathrm{ng} / \mathrm{mL}$ induce cell death [44].

An EGFR-effector screening was conducted by means of western blot analysis, upon exposing MDA-MB-468 cells to low $(1 \mathrm{ng} / \mathrm{mL})$ and high (100 $\mathrm{ng} / \mathrm{mL}$ ) EGF for various time points within a 2-hour period. Additionally, dose response experiments were conducted with increasing concentrations of EGF ligand for effector determinations as well. Protein effectors downstream of EGFR activation were expected to be upregulated with low ligand treatment if they had implications in cell growth. Conversely, effectors that were upregulated with high ligand treatment were assumed to have implications with cell death. After completing the effector screening, only two protein candidates were identified with potential correlation to upregulated EGFR with high ligand treatments: PKG and STAT3. This chapter serves to provide background of both effector candidates. 
PKG

Cyclic guanosine monophosphate (cGMP), a second messenger protein derived from GTP, elicits downstream signaling events through interactions with intracellular receptor proteins. It is involved in the regulation of smooth muscle tone, bone growth, platelet aggregation, and electrolyte and fluid homeostasis[78-80]. Nitric Oxide (NO), produced from nitric oxide synthase, is the first component involved in the activation of cGMP. NO activates soluble guanylate cyclases (GC-S), which increase cGMP levels. Cyclic-GMP then proceeds to bind to and activate a number of downstream substrates [79]. One of the more prominent receptor substrates of cGMP is the cGMP-dependent protein kinase (PKG). PKG was first discovered in 1970 in the muscle of lobster tails [81]. It is a serine/threonine protein kinase whose substrates include receptors, enzymes and ion channels [82].

The binding of 2 cGMP molecules is required for the complete activation of one PKG molecule [82]. PKG is a homodimer consisting of two of the same monomers, each of which contains a regulatory domain and a catalytic domain on one polypeptide chain [78-80, 82] (Fig. 3). Dimerization, auto-inhibition, and autophosphorylation all occur at the regulatory domain [79]. The catalytic domain contains a conserved threonine residue, whose phosphorylation is critical for relieving auto-inhibition, and essentially for kinase activity $[79,83]$. PKG exists in two homologous forms: PKG I and PKG II. PKG I is localized within the cytoplasm whereas PKG II is generally associated with the cell membrane [82]. Additionally, there are two isoforms of the type I PKG homologue: PKGI $\beta$ and 
A

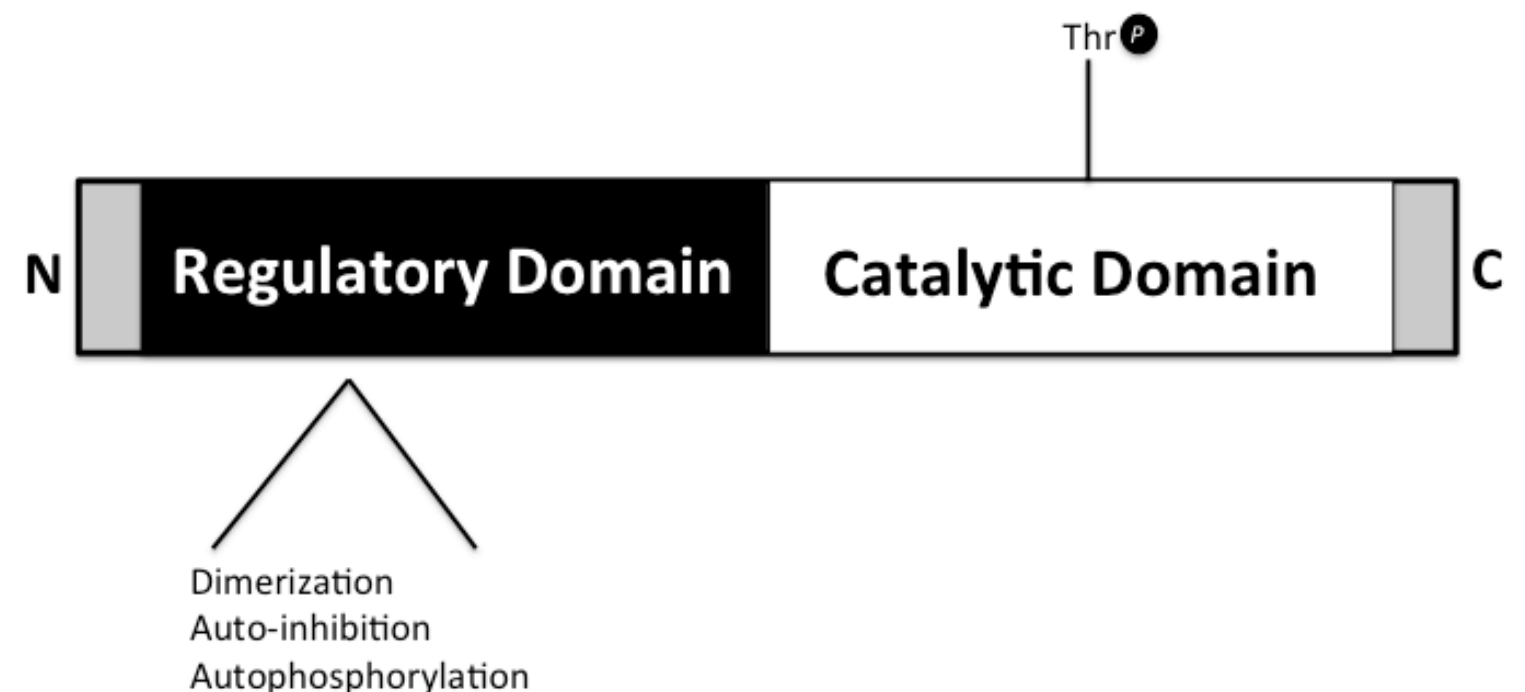

Autophosphorylation

B

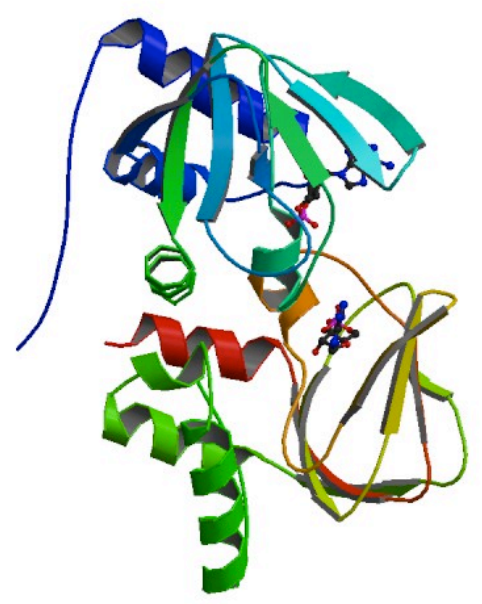

Figure 3. Domain (A) and Crystal (B) Structures of cyclic-GMP-dependent protein kinase (PKG). (Domain structure adapted from Francis et al., Pharmacol. Rev., 2010. Crystal Structure adapted from JJ Kim et al., PLOS One, 2011.) 
PKGla. These two isoforms are closely related, except in the N-terminal domain of the PKGla isoform, which has 16 fewer residues than the PKGI $\beta$ isoform [82]. More recently, the NO/cGMP/PKG pathway has been discovered to play critical roles in cell proliferation and chemoresistance in cancer cells [84, 85]. Studies have shown that cells that express PKGla and PKGI $\beta$ undergo a biphasic response when exposed to NO. Exposure to low levels of NO results in activation of PKGla specifically, leading to cell proliferation and suppression of apoptosis. This is because the PKGla isoform has a higher sensitivity to NO than the PKGI $\beta$ isoform. Conversely, a high level of NO leads to activation of both PKG isoforms, and tends to promote cell apoptosis and suppress cell proliferation. It is believed that the activation of PKGI $\beta$ by high-level NO contributes to the induction of apoptosis in cancer cells [86].

There have also been studies correlating EGFR activity and PKG activation. When OV2008 cells, an ovarian cancer cell line, were treated with increasing EGF ligand concentrations, immunoblot analyses displayed increased phosphorylation of serine-239 residue of VASP, a PKG-specific protein substrate. Western blot data from this study also exhibit increased phosphorylation of Src, a non-receptor tyrosine kinase protein that encodes for the SRC gene. These data suggest that activation of the EGFR and subsequent PKG activation occurs in a Src-dependent manner [85].

Recently, activation of PKG by cGMP has become of significant interest as a novel molecular tool in the induction of apoptosis in cancer [87]. PKG activation has been shown to induce dose dependent decreases in cell viability, 
as well as time dependent increases in caspases 3 and 9 activity within the MDAMB-468 cell line. The reduction in cell viability due to PKG activation was remarkably rescued with the addition of a PKG-specific antagonist to the MDAMB-468 cells [87]. Therefore, it is of interest to explore the activation of PKG and subsequent induction of PKG-mediated apoptosis in regard to EGFR-mediated apoptosis. Correlation of these two apoptotic pathways within the MDA-MB-468 cell line shows potential in identifying a novel protein with direct implications in the spatial regulation of the EGFR.

\section{STAT3}

In addition to PKG, STAT3 signaling was also shown to be upregulated with high concentrations of EGF ligand. Signal Transducer and Activator of Transcription (STAT) proteins were initially discovered as a family of cytoplasmbound transcription factors, which mediate normal cellular responses to growth factors, cytokines, and ligands $[88,89]$. STAT activation is critical for the mediation of certain biological processes, including cell proliferation, survival, differentiation, development and inflammation [90]. To date, there are seven known members of the STAT family expressed in mammalian tissue: STAT1, 2, $3,4,5 \mathrm{a}, 5 \mathrm{~b}$, and 6 . During activation, STAT proteins become phosphorylated at their unique critical tyrosine residues (Tyr705 for STAT3). This phosphorylation/activation process is mediated by growth factor receptor tyrosine kinases, and cytoplasmic kinases [88, 89]. Phosphorylation occurs at the cytoplasm, which induces STAT: STAT dimer formation between two monomers via SH2 domain interactions. From the cytoplasm, the activated STATS 
accumulate in the nucleus, where they initiate and mediate gene transcription by binding to DNA response elements [88]. This results in either upregulation or downregulation of the biological processes discussed previously, which are critical for cellular homeostasis.

Similarly to the EGFR, STAT proteins are implicated in cell growth and proliferation; however, they are upregulated in cancers and have been known to induce aberrant signaling in cancer cells. STAT3 has been reported to be constitutively phosphorylated in human cancer, and has been shown to promote tumor survival and cancer cell progression [90, 91]. Constitutive STAT3 activity has been reported in $30-60 \%$ of primary mammary malignancies [92]. One study reports that MDA-MB-468 cells exhibit constitutive activation of STAT3, and that upon inhibition using a pharmacological inhibitor (5,15-DPP), STAT3:DNA complexes decrease in a dose dependent manner of inhibitor [93]. These finding were not observed among the data described within this thesis.

Prior to being implicated in cancer, STAT3-programmed cellular death was found to be associated with and required for IL-6 induced cell death in myeloid leukemia [94] and mammary grand involution [95, 96]. After a woman is finished lactating, the involution process must occur in order to return the mammary gland to normal size of a "pre-pregnancy" state. This process is reliant on the post-translational upregulation of STAT3. This leads to downregulation of serine protease inhibitor $2 \mathrm{~A}$ (Spi2A), and upregulation of cathepsin $\mathrm{B}$. This upregulation of cathepsin B leads to the ultimate induction of apoptosis from the lysosome [97]. 
It appears as though STAT3 has been shown to play opposing roles in mammary tissue. In one instance, it has been shown to potentiate cell growth and invasion when constitutively active in cancer cells. Contrastingly, it has been implicated in cell death, being required for mammary gland involution, and even in leukemia. One of the focuses of this thesis is to define the role and activity of STAT3 in MDA-MB-468 cells.

In summary, cGMP dependent protein kinase (PKG) plays critical roles in smooth muscle function and regulation. PKG activity has been implicated in breast and ovarian cancer. More importantly, PKG activity has been shown to induce apoptosis in a dose dependent manner of a PKG agonist in MDA-MB-468 cells [98]. Identifying a correlation between PKG-mediated and EGFR-mediated apoptosis is therefore of interest for the progression of this research project. STAT3 has also been implicated in cancer. Although this protein is often associated with cell growth and survival, it is constitutively active in certain breast cancers, and required for cell death in certain contexts, such as post-lactation mammary gland involution [97]. It is unknown whether or not PKG and STAT3 have correlations with EGFR-induced apoptosis in MDA-MB-468 cells. It is now of interest to determine if they are in fact intermediary effectors within this process. 


\section{MATERIALS AND METHODS}

\section{Cell Line}

MDA-MB-468 cells were acquired from the American Type Culture Collection (ATCC) and maintained in Dulbecco's Modified Eagle Medium (DMEM) supplemented with $10 \%$ Fetal Bovine Serum (FBS), 1\% penicillin, 1\% streptomycin, and $2 \mathrm{mM}$ glutamine. The cells were maintained at incubation conditions of $37^{\circ} \mathrm{C}$ in $5 \% \mathrm{CO}_{2}$.

\section{Cell Viability Analyses}

\section{MTT assay}

MTT assays were conducted in order to assess cell viability utilizing the MDA-MB-468 cells. The MTT assay assesses mitochondrial dehydrogenase activity based on its ability to cleave the tetrazolium ring of the MTT reagent (Sigma Aldrich), and subsequently produce formazan. Only mitochondria of viable cells are capable of such cleavage. Cells were plated at a density of $5,000-10,000$ cells with DMEM supplemented with $10 \%$ FBS in a 96 well plate. After a 48 hour incubation period, the cells were washed with PBS and serum starved for 3 hours in DMEM supplemented with $0.2 \%$ BSA. The cells were then treated with various ligands and reagents in order to induce cell death. After appropriate incubation periods, the MTT reagent $(5 \mathrm{mg} / \mathrm{mL}$ in PBS) was added to each sample within the 96-well plate. The cells were then incubated for 2 hours 
at $37^{\circ} \mathrm{C}$ in the absence of $\mathrm{CO}_{2}$. An extraction buffer $(20 \%$ sodium dodecyl sulfate, $50 \% \mathrm{~N}$-dimethylformamide, $50 \% \mathrm{ddH}_{2} \mathrm{O}, 80 \%$ Acetic Acid, $1 \mathrm{M} \mathrm{HCl}$ ) was then added to all samples of the 96-well plate in order to extract and solubilize the formazan crystals. After an additional 30-minute incubation with extraction buffer at $37^{\circ} \mathrm{C}$ in the absence of $\mathrm{CO}_{2}$, the 96 -well plate was then analyzed on a BioTek Synergy HT plate reader and Gen5 BioTek software, at a wavelength of $570 \mathrm{~nm}$. The plate was then read a second time after 24 hours at the same wavelength.

\section{Alamarblue assay}

Alamarblue assays were also conducted in order to assess cell viability within the MDA-MB-468 cells. Resazurin, the active ingredient in the alamarblue reagent, is reduced to Resorufin in viable cells. Resorufin is highly fluorescent and viable cells enhance this fluorescence, which can be analyzed and quantified on a plate reader. Cells were plated at a density of 10,000 cells in DMEM supplemented with 10\% FBS in a 96-well plate. After a 48 hour incubation period, the cells were washed with PBS and serum starved overnight in serum free DMEM. The cells were then treated with reagents in order to induce either cell growth or death. The cells were then incubated in the presence of the various reagents for 16 hours. The alamarblue reagent was then added as $10 \%$ of the sample volume prior to a 2 hour incubation period. The 96-well plate was then analyzed on a BioTek Synergy HT plate reader and Gen5 BioTek software, at wavelengths of $530 \mathrm{~nm}$ (excitation) and $590 \mathrm{~nm}$ (emission). 


\section{Cell Lysate Preparation and Immunoblot Analyses.}

Cell lysates were acquired by washing the cells twice in PBS prior to the equilibration to $4^{\circ} \mathrm{C}$ and addition of RIPA lysis buffer for cell solubilization (150 $\mathrm{mm} \mathrm{NaCl}, 1 \%$ Nonidet P-40, 0.5\% deoxycholate, 0.1\% SDS, $50 \mathrm{~mm}$ Tris (pH 8.0), $10 \mathrm{~mm}$ sodium pyrophosphate, $100 \mathrm{~mm}$ sodium fluoride, $2 \mathrm{~mm}$ phenylmethyl sulfonyl fluoride). The lysis buffer/cell mixture was then rotated end-over-end for $10 \mathrm{~min}$ at $4{ }^{\circ} \mathrm{C}$, followed by a 10 minute centrifugation period at $15,000 \times \mathrm{g}$, also at $4{ }^{\circ} \mathrm{C}$. The protein concentration of the supernatant from each sample was then assessed by a BCA assay (Pierce), and samples were subjected to a 1:3 dilution in SDS sample buffer. Equivalent amounts of protein $(20-40 \mu \mathrm{g})$ were separated by either a $7.5 \%, 10 \%$ or $12 \%$ SDS-PAGE, prior to being transferred to nitrocellulose membranes. After being washed in a blocking reagent to prevent non-specific antibody binding, the membranes were exposed to various primary antibodies overnight at $4{ }^{\circ} \mathrm{C}$. The pY99 primary antibody (Santa Cruz) was used to detect phosphorylated tyrosine residues of the EGFR. The SC-03 primary antibody (Santa Cruz) was used to detect total (phosphorylated and non-phosphorylated) EGFR. The a-tubulin (Sigma Aldrich) as well as GAPDH (Santa Cruz) primary antibodies were used as loading controls to ensure equivalent amounts of protein were loaded into each lane. The following antibodies were also employed for studies within this thesis: pY1045 (Cell Signaling), pSTAT3(Tyr705; Cell Signaling), pSTAT1 (Tyr701; Cell Signaling), STAT3 (Cell Signaling), pMAPK (Cell Signaling), pAKT (Cell

Signaling), pSRC (Cell Signaling), pVASP (Ser239; Cell Signaling), VASP (Cell 
Signaling) and pBAD (Ser112; Cell Signaling). After a 1-hour incubation period with either anti-mouse (for pY99, $\alpha$-tubulin and GAPDH) or anti-rabbit (for SC-03, pSTAT1(Tyr701), pSTAT3(Tyr705), STAT3, pBAD (Ser112), pVASP(Ser239), VASP, pMAPK, pAKT, and pSRC) secondary antibodies, the membranes were washed in TBS-Tween and visualized by ECL reagent using a Fotodyne imaging system. All western blot data were analyzed and quantified using ImageJ software.

\section{Statistical Analyses}

Treatment groups within each individual MTT and Alamarblue experiments were quantified to the untreated control to generate percent viabilities for each experimental condition. These percentages for 3 individual experiments were then averaged together. Data acquired from both assays are reported as the means of the percent viabilities \pm standard error mean (SEM; $n=3)$ unless otherwise specified. An unpaired student t-test was then performed for the determination of significance. Each treatment group was compared to the untreated, serum free (SF), DMEM control. A $p$ value of less than 0.05 is designated significant, and is indicated by a single asterisk $\left(^{*}\right)$. A $p$ value of less than 0.01 is designated significant, and is indicated by two asterisks $\left(^{* *}\right)$. A $p$ value of less than 0.001 is designated very significant, and is indicated by three asterisks $\left.{ }^{* * *}\right)$. A $p$ value of less than 0.0001 is designated extremely significant, and is indicated by four asterisks $\left.{ }^{* * * *}\right)$. 


\section{RESULTS}

There were two major goals of this project, the first being to determine whether or not EGFR-induced apoptosis is ligand specific. The second goal was to identify proteins suspected of having direct implications in the EGFR-induced apoptotic process in the MDA-MB-468 cell line.

\section{EGF, BTC, and TGFA ligands induce dose dependent decreases in cell viability in MDA-MB-468 cell line.}

The purpose of this study was to investigate the possibility that different EGFR ligands have differential outcomes on EGFR-mediated viability and or induction of apoptosis. To assess this possibility, MDA-MB-468 cells were subjected to an MTT (3-(4,5-dimethylthiazol-2-yl)-2,5-diphenyltetrazolium bromide) cell viability assay upon exposure to EGF, BTC, and TGFA ligands for 16 hours total. All three of these ligands induce a dose dependent decrease in cell viability. All ligands showed statistical differences at high (16 nM) concentrations when quantified to the serum free DMEM control treated cells (Figure 4). 
EGF, BTC, and TGFA all induce a rounded cellular morphology in MDA-MB468 cells.

The purpose of this study was to observe the geometry and morphology of the MDA-MB-468 cells after exposure to EGF, BTC, and TGFA ligands. When cells undergo apoptosis, they physically shrink in size, and round in morphology. We observed the cells at various time points upon exposure to $16 \mathrm{nM}$ concentrations of each ligand. With increased time, we observed an increase in the amount of rounded cells versus cells with a viable, cobblestone-like morphology. At the latest, 24-hour time point, we observed that all cells exposed to all three ligands were morphologically rounded (Figure 5).

\section{EGF, BTC, and TGFA induce dose dependent increases in EGFR phosphorylation.}

The purpose of this experiment was to expose MDA-MB-468 cells to increasing concentrations of EGF, BTC, and TGFA ligands in order to compare and contrast any differences in EGFR phosphorylation patterns by means of western blot analysis. Cells were exposed to $0,0.16 \mathrm{nM}, 0.5 \mathrm{nM}, 1.6 \mathrm{nM}, 5 \mathrm{nM}$, and $16 \mathrm{nM}$ concentrations of each ligand for 1 hour. Western blot analyses confirm dose dependent increases in EGFR phosphorylation in response to each of the three ligands (Figure 6). 
Figure 4.

Dose Dependent Decreases in MDA-MB-468 Cell Viability After Exposure to EGF, TGFA, and BTC.

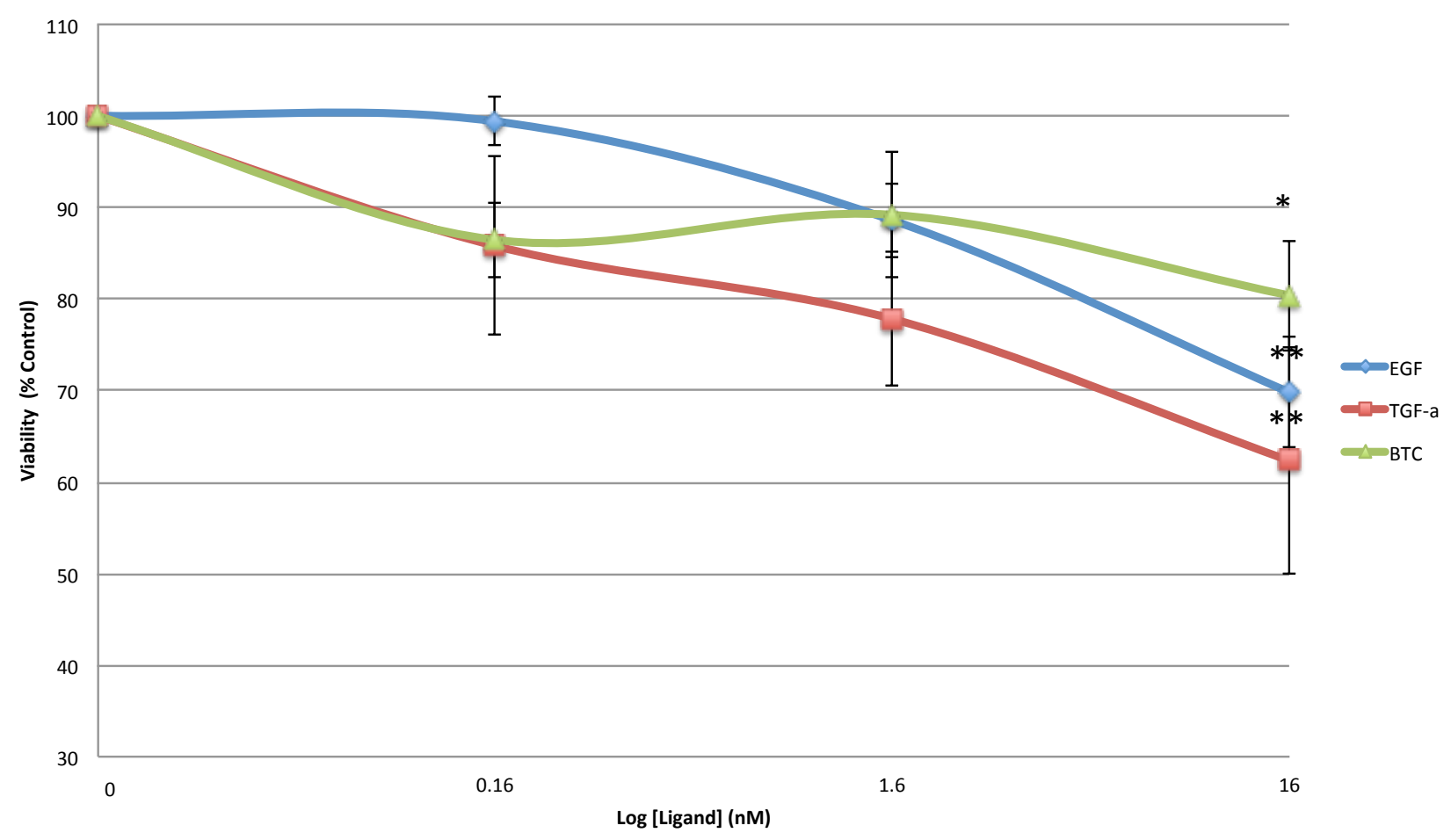

Figure 4. EGF, BTC, and TGFA ligands induce dose dependent decreases in cell viability in MDA-MB-468 cell line.

Results from an MTT (3-(4,5-dimethylthiazol-2-yl)-2,5-diphenyltetrazolium bromide) cell viability assay. EGF, BTC, and TGFA ligands all induce a dose dependent decrease in cell viability in the MDA-MB-468 cell line. Data are means of percent viability \pm SEM $(n=4)$. Data were subjected to an unpaired student TTest, each being compared to the untreated, serum free media control. An asterisk $\left({ }^{*}\right)$ indicates a significance of $p<0.05 .{ }^{* *}, p<0.01$. 
Figure 5.
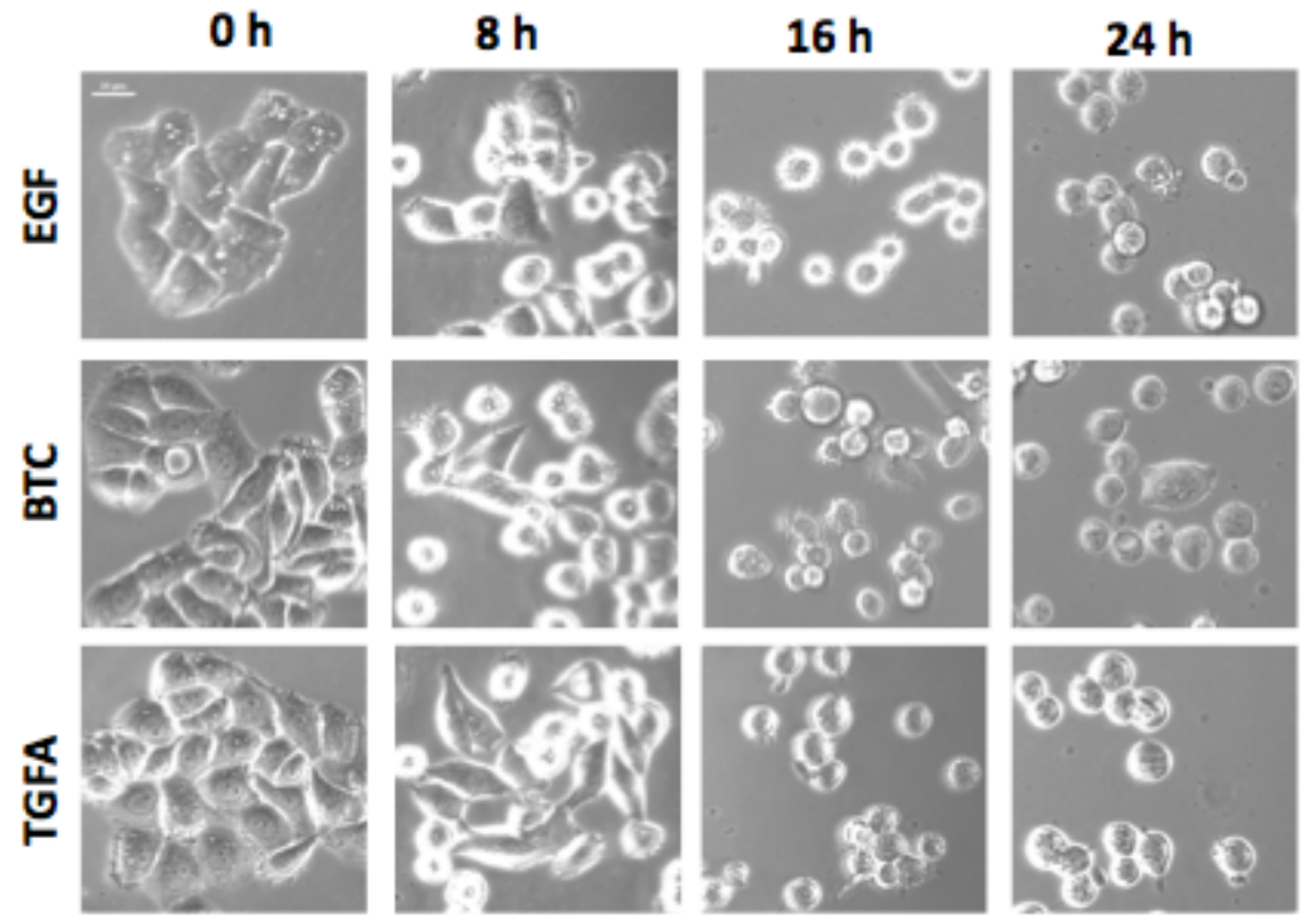

Figure 5. EGF, BTC, and TGFA ligands each induce a rounded cellular morphology in MDA-MB-468 cells.

Cells were exposed to $16 \mathrm{nM}$ concentrations of each ligand and then incubated for 24 hours total. Photomicrographs (20x) were taken at times 0h, 8h, 16h, and $24 \mathrm{~h}$ on a Nikon Eclipse Ti Eclipse widefield epifluorescence microscope.

Scale bar $=25 \mu \mathrm{m}$ 
Figure 6.

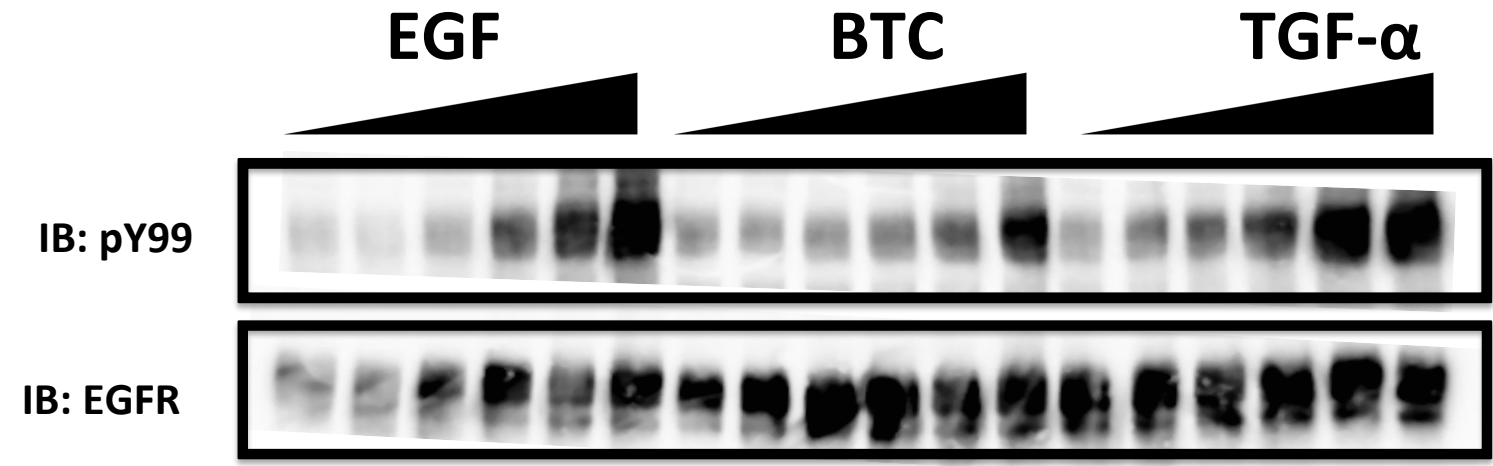

IB: $\alpha-$

Tubulin

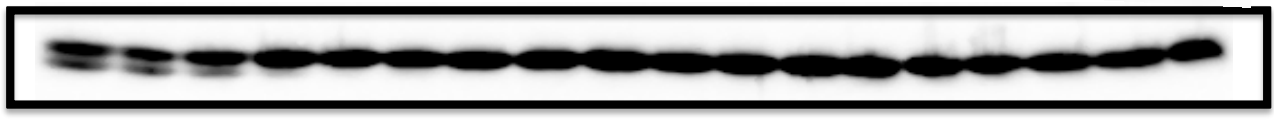

Figure 6. EGF, BTC, and TGFA induce dose dependent increases in EGFR phosphorylation.

After harvesting the cell lysates, $40 \mu \mathrm{g}$ of protein from each sample were resolved on a $7.5 \%$ SDS-PAGE. The protein was then transferred to a nitrocellulose membrane, which was then immunoblotted for either total phosphotyrosine containing proteins (p-EGFR) (pY99), Total EGFR (Sc-03), or loading control, $\alpha$-Tubulin. After incubation with appropriate secondary antibodies, the nitrocellulose membranes were imaged using a Fotodyne, ECL system. 
Identifying differences in EGFR-effector signaling between low $(1 \mathrm{ng} / \mathrm{mL})$ and high (100 ng/mL) EGF ligand exposures.

The purpose of this experiment was to expose MDA-MB-468 cells to low and high EGF concentrations in order to identify any differences in phosphorylation patterns and effector signaling. As previously mentioned, MDAMB-468 cells undergo cell growth when exposed to low $(1 \mathrm{ng} / \mathrm{mL})$ concentrations of EGF, and apoptosis when exposed to high ( $\geq 10 \mathrm{ng} / \mathrm{mL})$ EGF concentrations. The goal was to subject the cells to both low and high ligand, and then look at effector signaling in order to identify and differentiate effectors associated with cell growth, versus those associated with apoptosis. Cells were exposed to each of the ligand concentrations at various time points for a total of 120 minutes. Immunoblot analyses allowed for the assessment of pY1045, EGFR, pMAPK, pAKT, pSRC, pBAD, p-VASP-SER239, and GAPDH (Figure 7).

Mitogen-activated protein kinase 1 (MAPK), Proto-oncogene tyrosineprotein kinase sarcoma (SRC), Protein Kinase B (AKT), and Bcl-associated Death Protein (BAD) exhibit no significant differences in EGFR signaling at low versus high ligand concentrations.

These data are a quantification of three separate experiments of the western blot data, represented in figure 7 . Western blot data of all four effectors were quantified to the loading control for each experiment, GAPDH. No significant differences between low and high ligand exposures could be determined in phosphorylated, (p)-MAPK (Figure 8A), p-AKT (Figure 8B), p-SRC (Figure 8C), or p-BAD (Figure 8D) 
Figure 7.

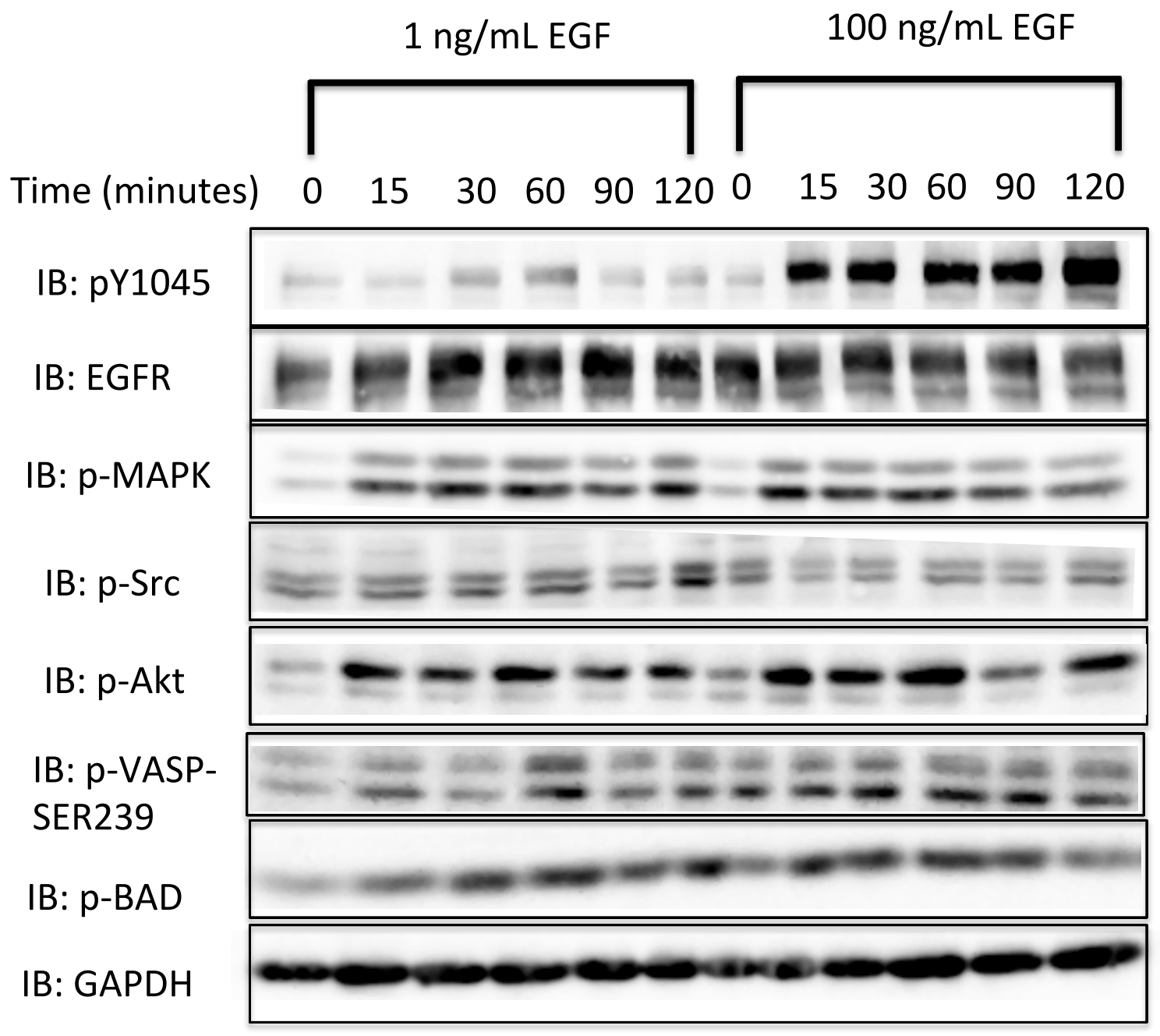

Figure 7. Identifying differences in EGFR-effector signaling between low $(1 \mathrm{ng} / \mathrm{mL})$ and high $(100 \mathrm{ng} / \mathrm{mL})$ EGF ligand exposures.

After harvesting the cell lysates, $20 \mu \mathrm{g}$ of protein from each sample were resolved on a $12 \%$ SDS-PAGE. The protein was then transferred to a nitrocellulose membrane, which was then subjected to immunoblot analyses, to assess for pY1045, EGFR, pMAPK, pAKT, pSRC, pBAD, p-VASP-SER239, and GAPDH phosphorylation. After incubation with appropriate secondary antibodies, the nitrocellulose membranes were imaged using a Fotodyne, ECL system. 
Figure 8.
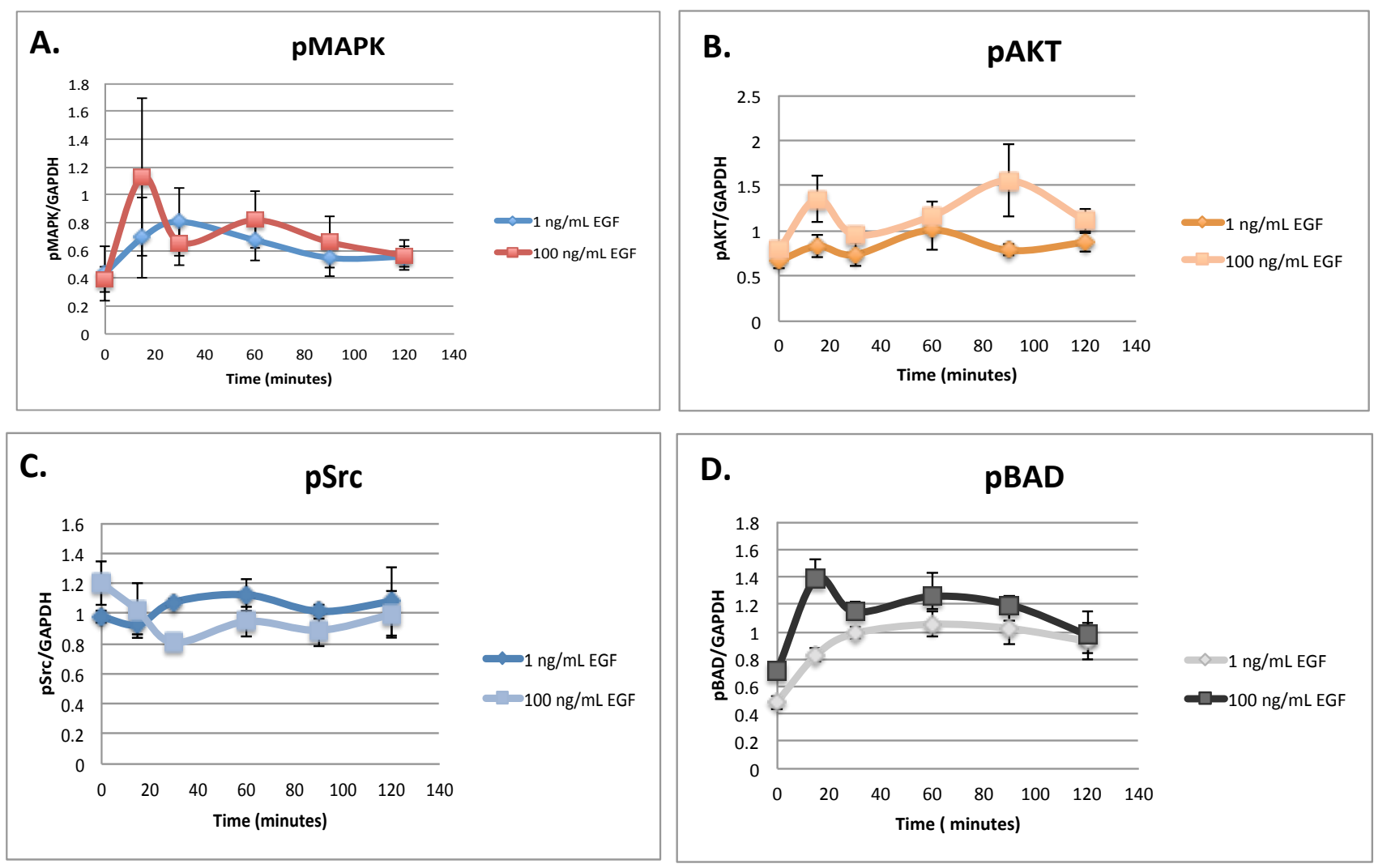

Figure 8. MAPK, SRC, AKT, and BAD exhibit no significant differences in EGFR signaling at low versus high ligand concentrations.

Quantification of three separate experiments of the western blot data represented in Figure 7. Error bars are expressed as \pm SEM. No significant differences in signaling between low and high EGF ligand exposures could be determined in phosphorylated, (p)-MAPK (A), p-AKT (B), p-SRC (C), or p-BAD (D). 
Increases in EGF ligand concentration elicit a dose dependent increase in p-VASP(SER239) phosphorylation.

The purpose of this experiment was to assess PKG activity, by means of a p-VASP-SER239 antibody, in order to determine if its activity had any correlation with EGFR activity. A dose response was conducted, using 0, 1, 3, 10, 30 and $100 \mathrm{ng} / \mathrm{mL}$ concentrations of EGF ligand. Data confirm that increases in EGF ligand induce dosed dependent increases in p-VASP-SER239 phosphorylation (Figure 9A). Western blot analyses of pY1045 and p-VASP-Ser239 from 3 experiments were both analyzed and quantified to western blots of total EGFR and total VASP respectively (Figures 9B and 9C). Data from figure 9D are a quantification of three experiments of the p-VASP-SER239 western blot data, represented in Figure 7.

PKG agonist, 8-Bromo-cGMP, induces a dose dependent decrease in cell viability.

The purpose of this experiment was to assess PKG-activation and its potential role in the induction of apoptosis in MDA-MB-468 cells. Literature has shown that PKG is able to induce apoptosis within this cell line. It was of interest to determine if PKG induction of apoptosis had correlation to EGFR-induced apoptosis. We decided to first assess cell viability by means of an MTT assay in order to configure an optimal concentration for Annexin $\mathrm{V}$ assay, a more accurate measure of apoptosis. MDA-MB-468 cells were subjected to increasing concentrations ( $100 \mu \mathrm{M}, 300 \mu \mathrm{M}, 500 \mu \mathrm{M}, 1 \mathrm{mM}, 3 \mathrm{mM}, 10 \mathrm{mM})$ of PKG activator, 8-Bromo-cGMP (8-Br-cGMP; Sigma) for 48 hours total. Cells treated in serum free 
Figure 9.

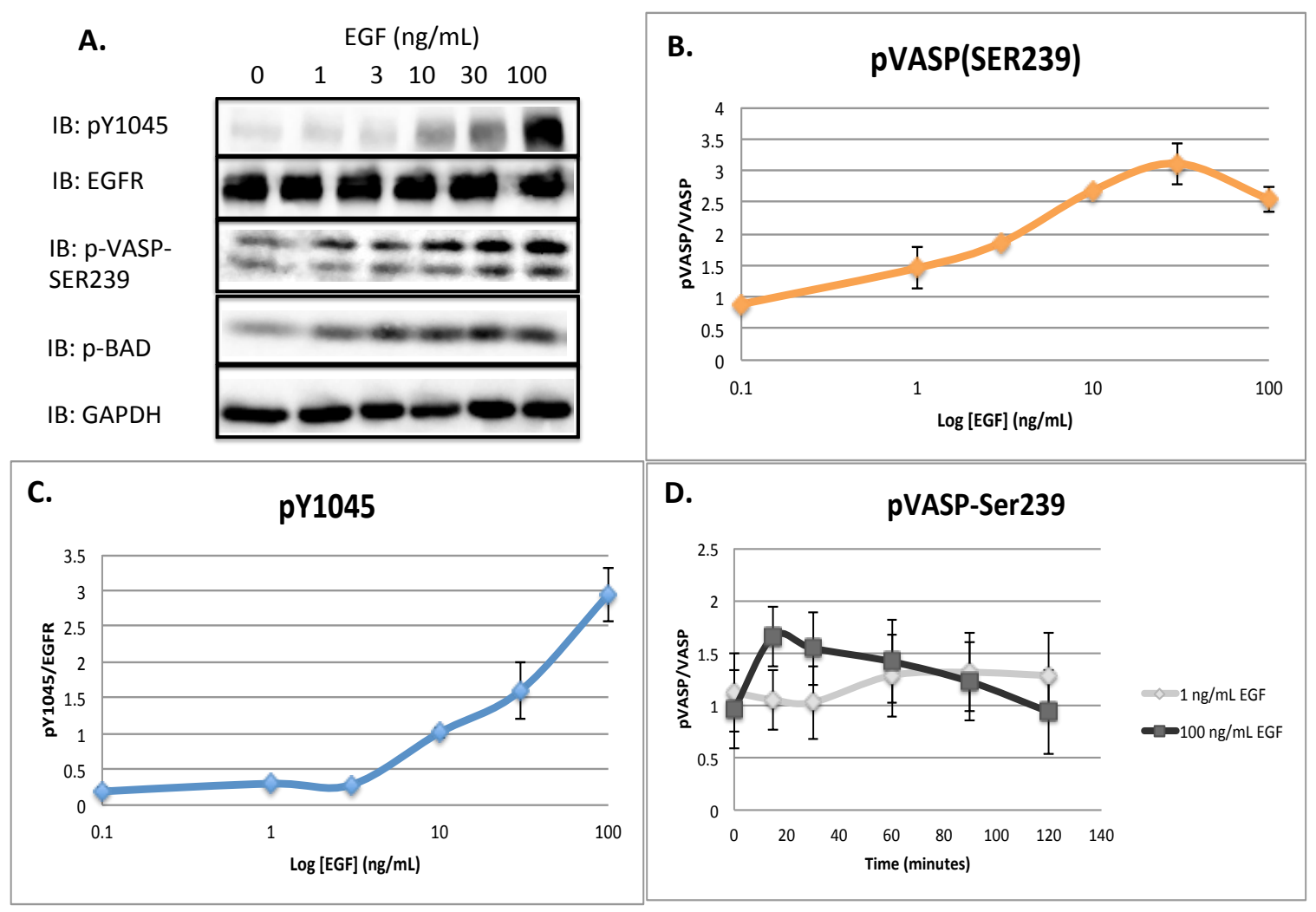

Figure 9. Increases in EGF ligand concentration elicit a dose dependent increase in p-VASP(SER239) phosphorylation.

A dose response was conducted, using $0,1,3,10,30$ and $100 \mathrm{ng} / \mathrm{mL}$ concentrations of EGF ligand. Cells were exposed to the 5 different ligand concentrations for 30 minutes. Twenty $\mu \mathrm{g}$ of protein per sample were then resolved on a 12\% SDS-PAGE (A). Western blot data of p-VASP-SER239 (B) and pY1045 (B) blot membranes were quantified to total VASP and total EGFR, respectively. Data from Figure 9D are a quantification of three experiments of the p-VASP-SER239 western blot data, represented in Figure 7. Error bars are expressed as \pm SEM. 
DMEM (SF) and DMEM supplemented in 10\% FBS (10\% FBS) served as positive controls for viability. Cells treated with 16 nM EGF and $100 \mathrm{nM}$ Staurosporine (STS) served as negative controls for viability, and positive controls for apoptosis. Data from this experiment exhibit a clear dose dependent decrease in MDA-MB-468 cell viability in response to the dose dependent increases in PKG activation (Figure 10).

The use of PKG agonist, 8-Bromo-cGMP, confirms that PKG does not elicit EGFR phosphorylation.

The purpose of this experiment was to assess the efficacy of commercially available PKG inhibitors, as well as the ability of a PKG agonist to activate the EGFR. The only way of determining if PKG plays a true intermediary role in EGFR-induced apoptosis is to reduce PKG activity, and then subsequently assess this effect on apoptosis and viability. The PKG antagonist, (D)-DT-2 (Biolog Life Science Institute; $I_{50} \sim 12 \mathrm{nM}$ ) was used at $1.25 \mathrm{nM}, 12.5 \mathrm{nM}, 25$ $\mathrm{nM}, 125 \mathrm{nM}, 500 \mathrm{nM}$, and $1.25 \mu \mathrm{M}$ concentrations. The PKG agonist, 8-BrcGMP, was used at $10 \mu \mathrm{M}, 30 \mu \mathrm{M}, 100 \mu \mathrm{M}, 300 \mu \mathrm{M}, 1 \mathrm{mM}$, and $3 \mathrm{mM}$ concentrations, with an accompanying vehicle control comprised of $33 \% \mathrm{ddH}_{2} \mathrm{O}$. The 8-Br-cGMP agonist was employed within this assay as a positive control for pVASP(Ser239) phosphorylation, whereas cells treated in serum free DMEM (SF) served as negative controls for EGFR (pY1045) and pVASP(Ser239) phosphorylation (Figure 11A). The PKG antagonist, Rp-8Br-PET-cGMPs (Biolog Life Science Institute; $\mathrm{IC}_{50} \sim 25 \mu \mathrm{M}$ ) was used at $1 \mu \mathrm{M}, 3 \mu \mathrm{M}, 10 \mu \mathrm{M}, 30 \mu \mathrm{M}$, and $100 \mu \mathrm{M}$ concentrations, with an accompanying vehicle control comprised of 
0.38\% Dimethylformamide (DMF) in DMEM (Figure 11B). The PKG agonist, 8Br-cGMP, was used at $300 \mu \mathrm{M}, 1 \mathrm{mM}, 1.3 \mathrm{mM}, 2 \mathrm{mM}$, and $3 \mathrm{mM}$ concentrations, with an accompanying vehicle control comprised of $33 \% \mathrm{ddH}_{2} \mathrm{O}$ in DMEM. The 8Br-cGMP agonist was employed within this assay as a positive control for pVASP(Ser239) phosphorylation, whereas cells treated in serum free DMEM (SF) served as negative controls for EGFR (pY1045) and pVASP(Ser239) phosphorylation (Figure 11B). Although neither antagonist functioned as sufficiently as anticipated, it is clear that PKG activation with 8-Bromo-cGMP does not induce EGFR (pY1045) phosphorylation and subsequent activation.

\section{PSTAT3(Tyr705) is upregulated in both a dose and time dependent manner, at high EGF ligand concentrations.}

The purpose of these experiments was to assess STAT3 signaling when exposed to low and high EGF concentrations. STAT3 was one of the proteins assessed in our initial EGFR-effector screening. MDA-MB-468 cells were subjected to 2-hour time course experiments (Figure 12A. and 12B.), and 30minute dose response experiments (Figure 12C. and 12D.) at low and high ligand concentrations, as described previously. Data confirm that both STAT1 and STAT3 are upregulated in a time dependent manner, at $100 \mathrm{ng} / \mathrm{mL}$ EGF ligand concentrations. At $1 \mathrm{ng} / \mathrm{mL}$ EGF, minimal STAT1 activation and no STAT3 activation was observed. Data from dose response experiments, utilizing 1, 3, 10 , 30 and $100 \mathrm{ng} / \mathrm{mL}$ EGF, confirm that STAT3 is upregulated in a dose dependent manner. 
Figure 10.

\section{PKG Agonist Induces a Dose Dependent Decrease in Cell Viability in MDA-MB-468 Cells.}

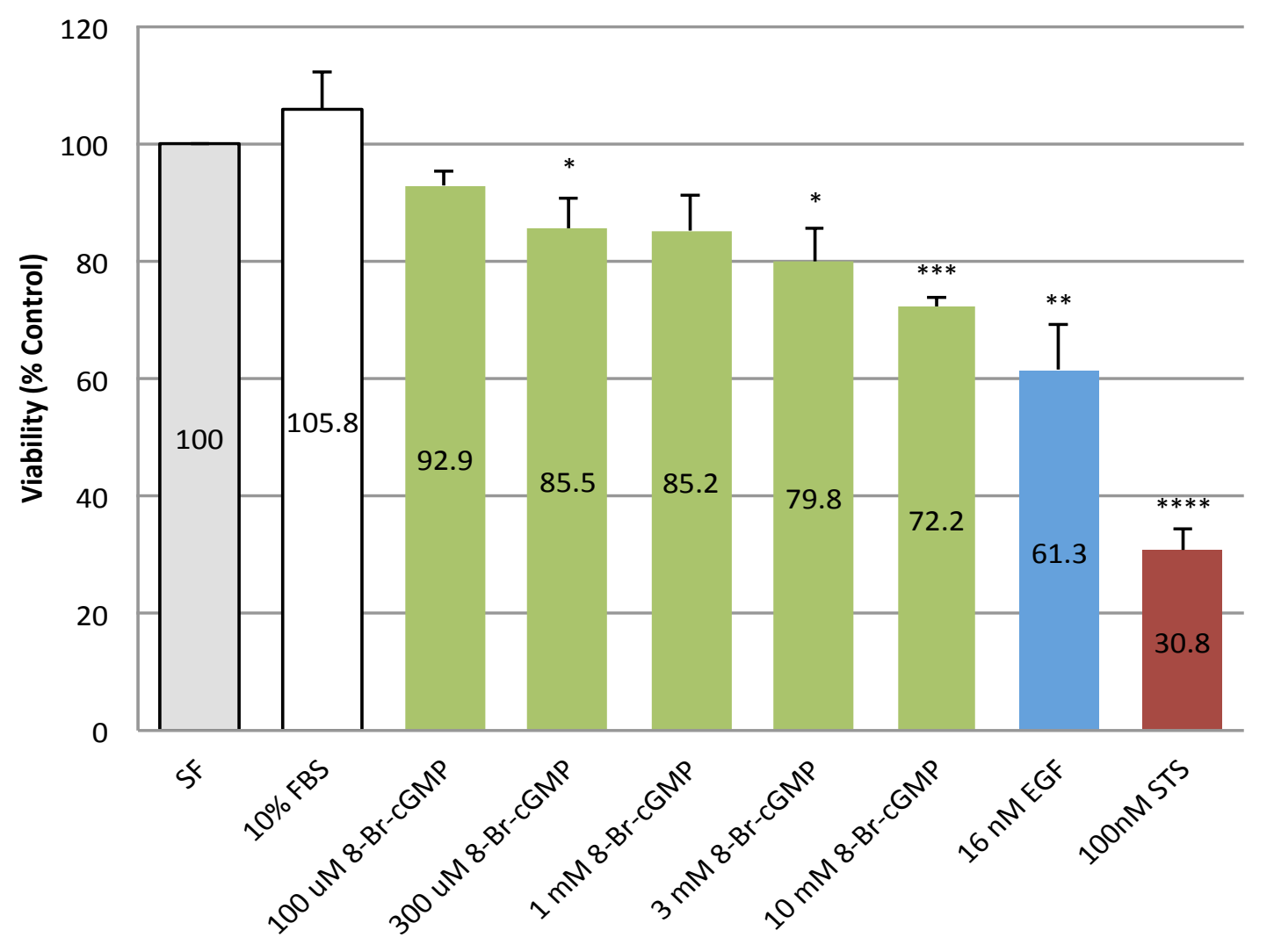

Figure 10. Dose dependent increase in PKG activator, 8-Bromo-cGMP, induces a dose dependent decrease in cell viability.

Results from an MTT (3-(4,5-dimethylthiazol-2-yl)-2,5-diphenyltetrazolium bromide) cell viability assay. Increasing concentrations of a PKG activator induce a dose dependent decrease in cell viability within the MDA-MB-468 cell line after 48 hours. Data are means of percent viability $\pm \operatorname{SEM}(n=3)$. Data were subjected to an unpaired student T-Test, each being compared to the untreated, serum free (SF) DMEM control. An asterisk $\left(^{*}\right)$ indicates a significance of $p<0.05 . \quad{ }^{* *}$, $p<0.01 .{ }^{* * *}, p<0.001 . \quad{ }^{* * * *}, p<0.0001$. 
Figure 11.

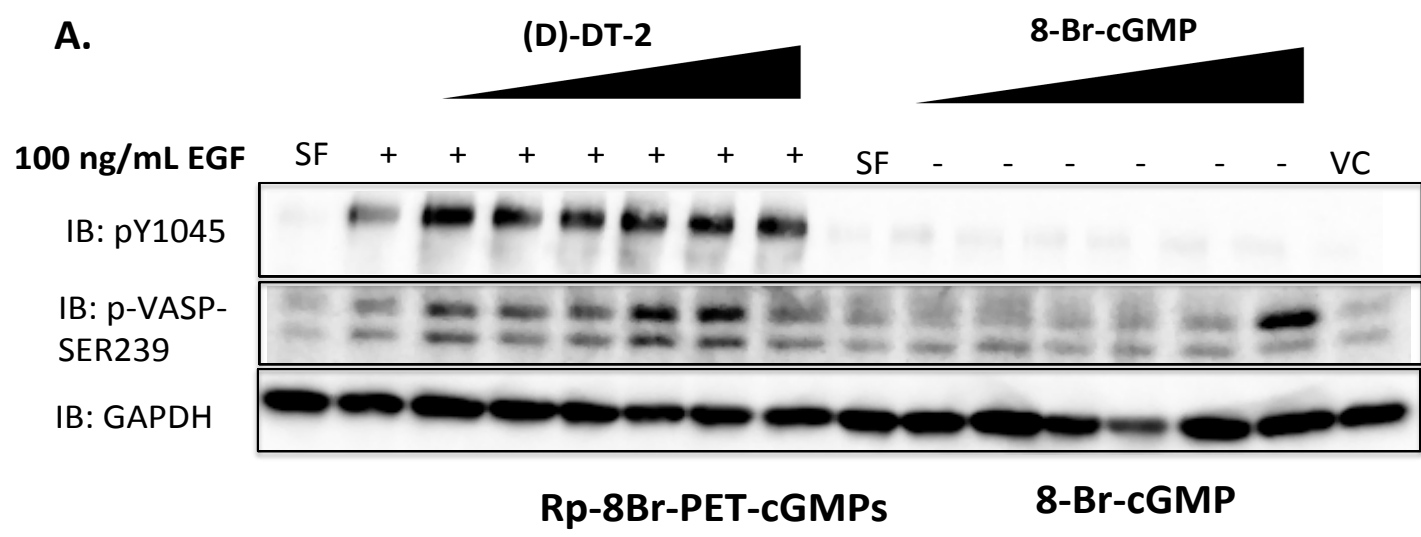

B.

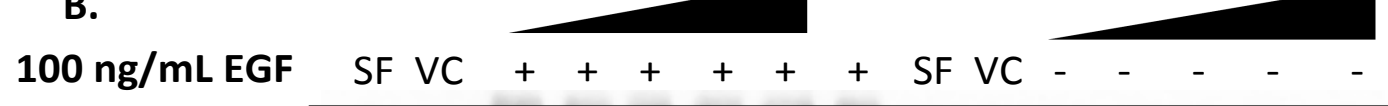

IB: pY1045

IB: EGFR

IB: pVASP-

SER239

IB: VASP

IB: GAPDH

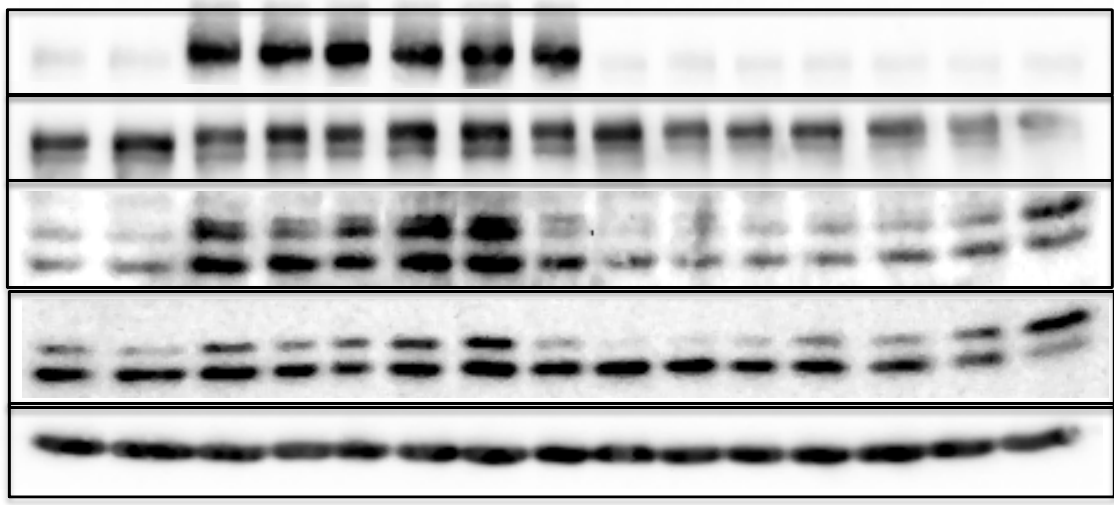

Figure 11. The use of PKG agonist, 8-Bromo-cGMP, confirms that PKG does not elicit EGFR phosphorylation.

A. The PKG antagonist, (D)-DT-2 (IC $\left.\mathrm{I}_{50} \sim 12 \mathrm{nM}\right)$ was used at $1.25 \mathrm{nM}, 12.5 \mathrm{nM}$, $25 \mathrm{nM}, 125 \mathrm{nM}, 500 \mathrm{nM}$, and $1.25 \mu \mathrm{M}$ concentrations. The PKG agonist, 8-BrcGMP, was used at $10 \mu \mathrm{M}, 30 \mu \mathrm{M}, 100 \mu \mathrm{M}, 300 \mu \mathrm{M}, 1 \mathrm{mM}$, and $3 \mathrm{mM}$ concentrations, with an accompanying vehicle control (VC) comprised of $33 \%$ $\mathrm{ddH}_{2} \mathrm{O}$ in DMEM. Forty $\mu \mathrm{g}$ of protein per sample were then resolved on a $12 \%$ SDS-PAGE.

B. The PKG antagonist, Rp-8Br-PET-cGMPs $\left(\mathrm{IC}_{50}=25 \mu \mathrm{M}\right)$ was used at $1 \mu \mathrm{M}, 3$ $\mu \mathrm{M}, 10 \mu \mathrm{M}, 30 \mu \mathrm{M}$, and $100 \mu \mathrm{M}$ concentrations, with an accompanying vehicle control comprised of $0.38 \%$ Dimethylformamide (DMF). The PKG agonist, 8-BrcGMP, was used at $300 \mu \mathrm{M}, 1 \mathrm{mM}, 1.3 \mathrm{mM}, 2 \mathrm{mM}$, and $3 \mathrm{mM}$ concentrations, with an accompanying vehicle control (VC) comprised of $33 \% \mathrm{ddH}_{2} \mathrm{O}$ in DMEM. Twenty $\mu \mathrm{g}$ of protein per sample were then resolved on a $12 \%$ SDS-PAGE. 
Figure 12.
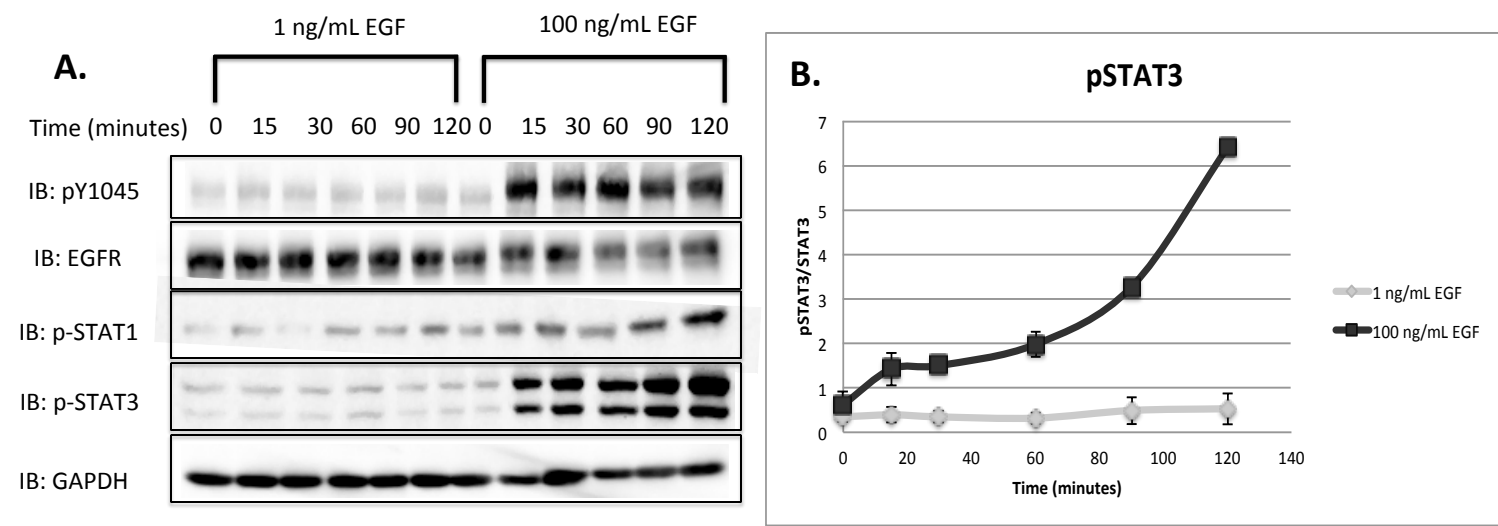

$\mathrm{EGF}(\mathrm{ng} / \mathrm{mL})$

c.
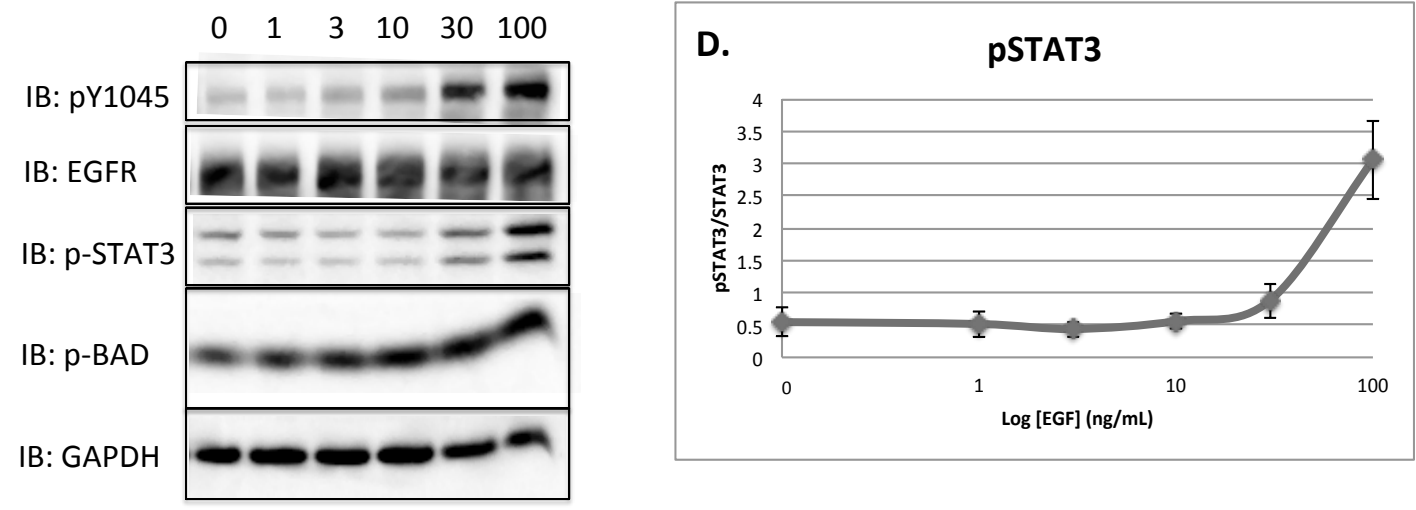

Figure 12. pSTAT3(Tyr705) is upregulated in both a dose and time dependent manner, at high EGF ligand concentrations.

A. MDA-MB-468 cells were subjected to a 2-hour time course experiment, and were exposed to $1 \mathrm{ng} / \mathrm{mL}$ and $100 \mathrm{ng} / \mathrm{mL}$ EGF concentrations at various time points within the 2-hour window frame $(0,15,30,60,90$, and 120 minutes). Thirty $\mu \mathrm{g}$ of protein per sample were then resolved on a $12 \%$ SDSPAGE.

B. Quantification of three independent time course experiments, represented in figure 12A. Error bars are expressed as \pm SEM.

C. The cells were also subjected to a 30-minute dose response experiment, and were exposed to ligand concentrations of $1,3,10,30$ and $100 \mathrm{ng} / \mathrm{mL}$ EGF.

D. Quantification of three independent dose response experiments, represented in figure $12 \mathrm{C}$. Error bars are expressed as \pm SEM. 


\section{Commercially available STAT3 antagonists exhibit non-specific inhibition of STAT3 in MDA-MB-468 cells.}

The purpose of these experiments was to utilize 2 commercially available STAT3 inhibitors in order to examine the role of STAT3 in the induction of EGFRmediated apoptosis. MDA-MB-468 cells were exposed to increased concentrations of 5,15-DPP (Sigma; IC 50 $=280 \mathrm{nM}$; Figure 13A.) and STATTIC (Sigma; $\mathrm{IC}_{50}=5.1 \mu \mathrm{M}$; Figure 13B.) STAT3 inhibitors. In addition to the dose dependent decrease in pSTAT3(Tyr705) that each inhibitor induced, both inhibitors also induced dose dependent inhibition of phosphorylated EGFR (pY1045).

\section{STATTIC induces a dose dependent decrease in cell viability.}

Upon completion of dose response, western blot experiments with the STATTIC inhibitor, cytotoxicity was observed with each utilized concentration of inhibitor. Therefore, Alamarblue, cell viability experiments were employed in order to assess and quantitate the extent of toxicity STATTIC induced within MDA-MB-468 cells. STATTIC was reconstituted in DMF and cells were treated with an accompanying vehicle control of $0.31 \%$ DMF in DMEM (Figure 14A). It was also of interest to determine if STATTIC used in combination with $100 \mathrm{ng} / \mathrm{mL}$ EGF ligand induced more apoptosis than STATTIC alone. Alamarblue experiments confirm that with low ( $3 \mu \mathrm{M})$ STATTIC, $100 \mathrm{ng} / \mathrm{mL}$ of EGF appears to slightly enhance the extent of apoptosis; however, the concentrations of both EGF and STATTIC alone induced over $50 \%$ cell death. Therefore, it was not possible to fully describe the interaction of the two components in combination with one another (Figure 14B). 
Figure 13.
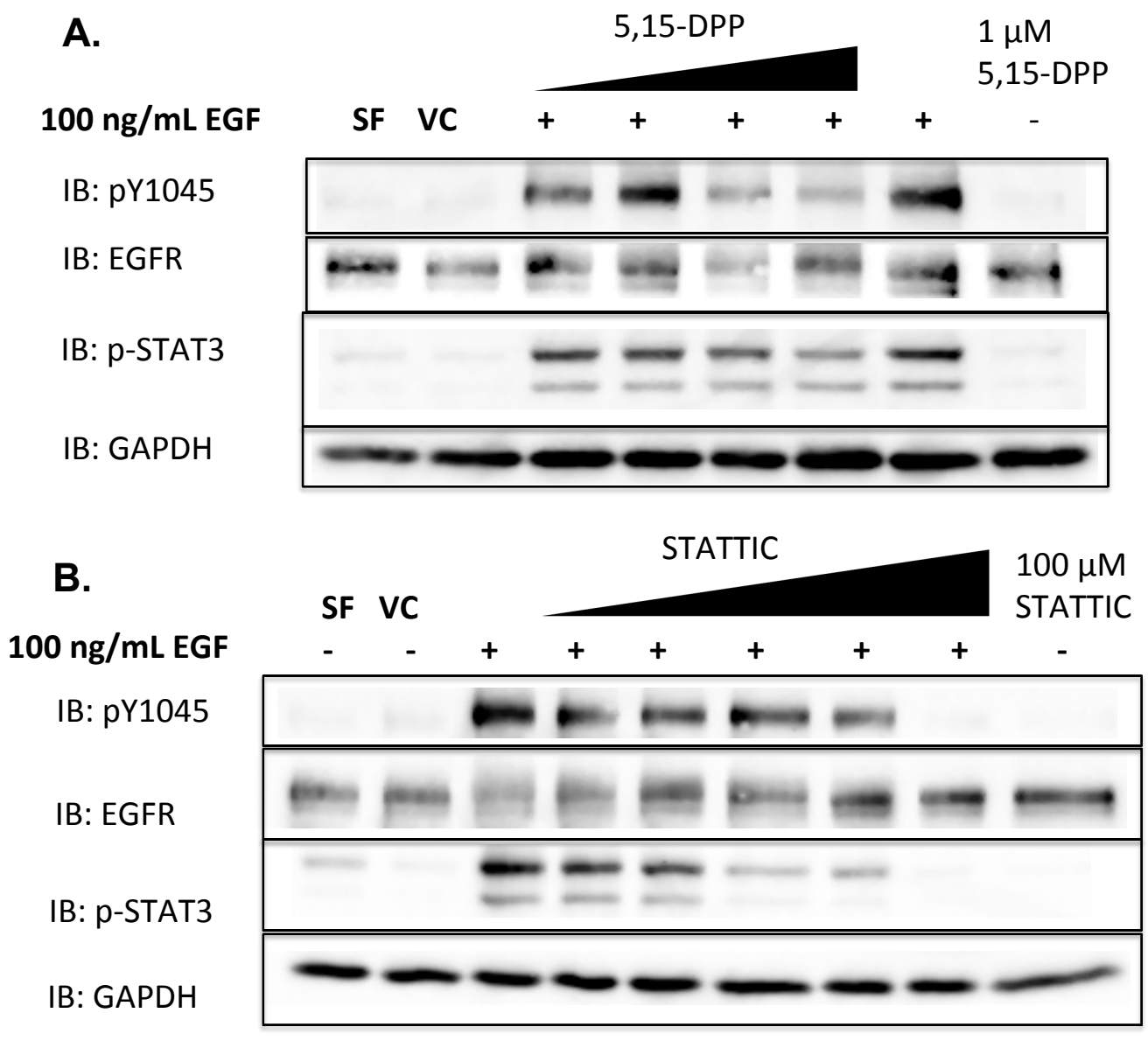

Figure 13. Commercially available STAT3 antagonists exhibit non-specific inhibition of STAT3 in MDA-MB-468 cells.

A. A dose response experiment was conducted, utilizing $30 \mathrm{nM}, 100 \mathrm{nM}, 300$ $\mathrm{nM}$, and $1 \mu \mathrm{M}$ concentrations of the 5,15-DPP STAT3 inhibitor. Cells were also treated with a vehicle control (VC) of $0.34 \%$ DMF in DMEM. Upon harvesting cell lysates, $40 \mu \mathrm{g}$ of protein per sample were then resolved on a $12 \%$ SDS-PAGE.

B. A second STAT3 inhibitor, STATTIC, was employed at $1 \mu \mathrm{M}, 3 \mu \mathrm{M}, 10$ $\mu \mathrm{M}, 30 \mu \mathrm{M}$, and $100 \mu \mathrm{M}$ concentrations. The cells were also treated with a vehicle control (VC) of $0.38 \%$ DMF in DMEM. Upon harvesting cell lysates, $20 \mu \mathrm{g}$ of protein per sample were then resolved on a $12 \%$ SDSPAGE. 
Figure 14.

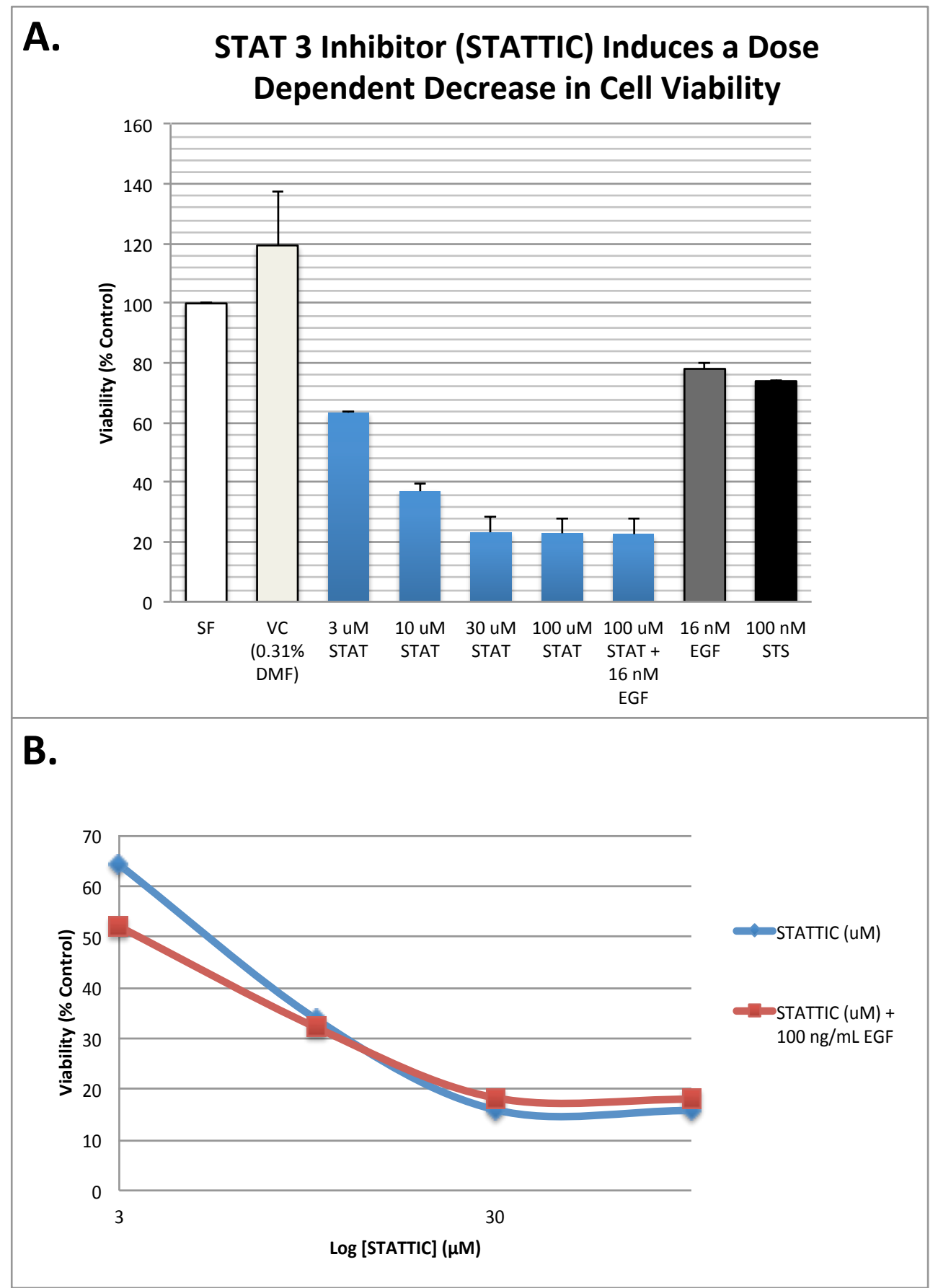

Figure 14. STATTIC induces a dose dependent decrease in cell viability.

A. STAT3 inhibitor, STATTIC, was employed in order to examine and quantify its extent of cytotoxicity. EGF and staurosporine treatments served as positive controls for apoptosis $(n=2 \pm$ SEM). B. STATTIC was used in combination with $100 \mathrm{ng} / \mathrm{mL}$ EGF ligand to determine if the combination treatment enhanced the induction of apoptosis $(n=1)$. 
siRNA targeting STAT3 are able to significantly reduce STAT3 activity.

The purpose of this experiment was to determine if MDA-MB-468 cells could be subjected to siRNA knockdown. This determination is critical for employment of subsequent siRNA, and subsequent analysis of cell viability and apoptosis. In order to assess this, siRNA targeting STAT3 (Dharmacon; SO2427018G) were employed. Western blot analyses confirm that with the addition of both STAT3 siRNA, vast reduction in phosphorylated and total STAT3 (78\% reduction) is observed in MDA-MB-468 cells (Figure 15). 
Figure 15.

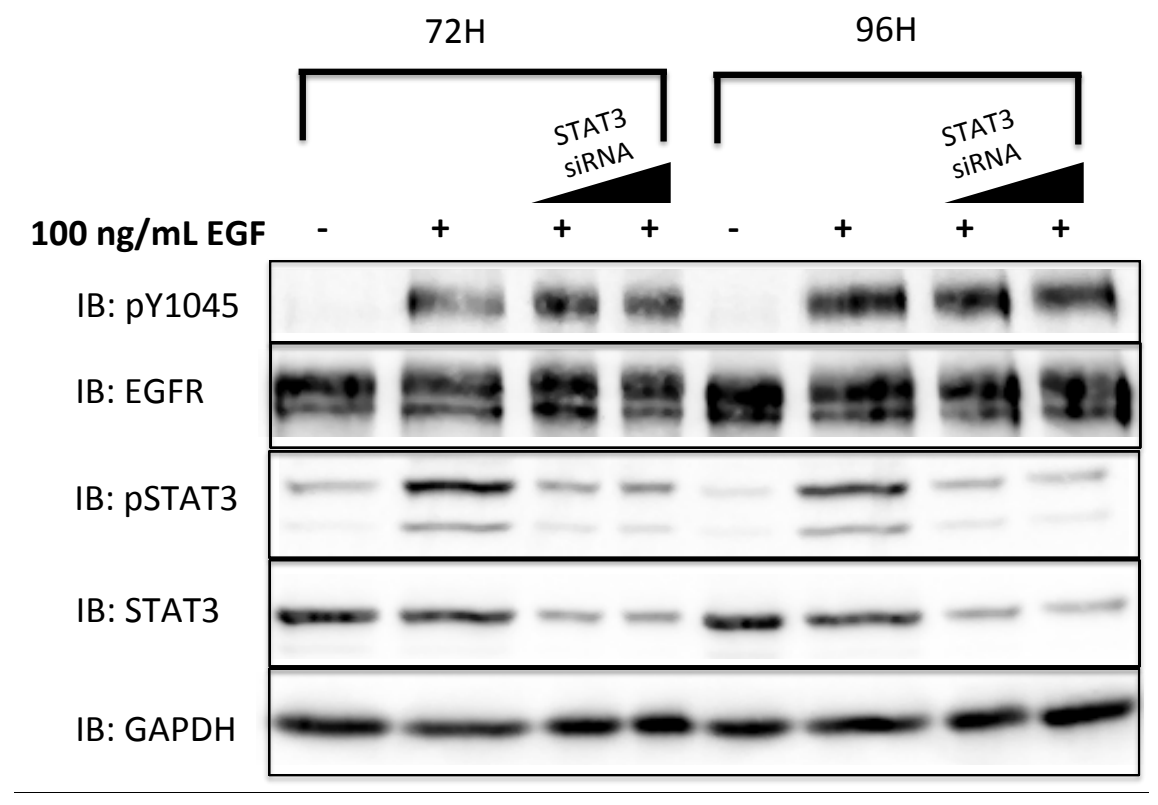

Figure 15. siRNA targeting STAT3 are able to significantly reduce STAT3 activity. MDA-MB-468 cells were subjected to $50 \mathrm{nM}$ and $100 \mathrm{nM}$ STAT3 siRNA for 72 and 96 hours. After allotted time points, cells were harvested, and $20 \mu \mathrm{g}$ of protein per sample were then resolved on a $10 \%$ SDS-PAGE. 


\section{DISCUSSION}

Initial intentions of this study were to understand the molecular mechanisms that elicit EGFR-mediated apoptosis. In doing so, MDA-MB-468 cells were exposed to various endogenous EGFR ligands and determine their individual outcomes on cell viability. It was of interest to determine if the EGFR had ligand specificity within this cell line. Knowing that EGF, BTC, and TGFA ligands each cause differential endocytic sorting of the receptor [35], it is possible that these ligands can differentially affect cell viability and apoptosis as well. If the ligands induce different cellular morphologies and phenotypes, this information could be useful in determining how the EGFR is spatially regulated within this cell line. We decided to first assess cell viability in order to determine optimal time points and concentrations for subsequent apoptosis analyses. Results from the MTT (3-(4,5-dimethylthiazol-2-yl)-2,5-diphenyltetrazolium bromide) cell viability assay confirm that the MDA-MB-468 cells undergo dose dependent decreases in cell viability in response to all three ligands (Figure 4).

Cell morphology was assessed upon exposure of the MDA-MB-468 cells to high (16 nM) concentrations of each ligand. When cells undergo cell death, they tend to round morphologically. We wanted to physically assess the condition of the cell by taking bright field images of the cells with increased time. The 24hour images of each of the three-ligand treatment groups showed the same 
rounded cellular morphologies, indicative of cell death (Figure 5). These data confirm the findings within the MTT analyses.

Lastly, phosphorylation patterns were assessed after exposure to increasing concentrations of each ligand $(0,0.16 \mathrm{nM}, 0.5 \mathrm{nM}, 1.6 \mathrm{nM}, 5 \mathrm{nM}, 16$ $\mathrm{nM})$. This assay was conducted in order to assess for any variations in EGFR phosphorylation patterns. Although BTC ligand had slightly reduced phosphorylation in comparison to EGF and TGFA ligands, all 3 ligands induced dose dependent increases in phosphorylation, with similar phosphorylation patterns (Figure 6).

From these three experiments, we can confidently confirm that different EGFR ligands do not induce any variation in cell integrity or morphology within the MDA-MB-468 cell line. All three of these ligands induce cell death morphology, decreases in cell viability, and have similar EGFR phosphorylation patterns within our cell line of interest. Therefore, we conclude that EGFRmediated apoptosis from the endosomes is not ligand specific. This determination means that there is a requirement for a different experimental approach in order to understand the effector proteins and mechanisms involved in EGFR-mediated apoptosis and spatial regulation.

The findings within these studies were ultimately anticipated. We suspect that EGFR-mediated apoptosis is a regulatory mechanism of cancers that hyperexpress this receptor. Low concentrations of EGF ligand results in a lower ratio of activated receptors, leading to cell growth. Conversely, with high EGF ligand concentrations, a larger amount of receptors are activated, and cell death occurs 
[44]. We speculate that in MDA-MB-468 cells, high ligand levels elicits high receptor activation at cell membrane, resulting in the need for an immense level of ligand:receptor internalization and trafficking at the same time. The endocytic machinery required for the internalization and trafficking of the receptor is incapable of efficiently sorting the large number of ligand:receptor complexes, causing saturation of the endocytic machinery. As a result of this saturation, the increasingly high levels of activated receptors accumulate at the early endosome. This causes a disruption in normal cell homeostasis, inevitably resulting in apoptosis. We ultimately hypothesize that the accumulation at the endosome as a result of high receptor activation is the underlying culprit of EGFR-mediated apoptosis in the MDA-MB-468 cell line. Therefore, higher levels of any natural receptor ligand will still deduce the same extent of receptor activation, and result in cell death.

It is known that the biological sequence of receptor tyrosine kinases entails the recruitment of downstream signaling molecules to the phosphorylated tyrosine residues of the activated receptor dimer [4]. These signaling molecules are often intermediates in signaling cascades that are ultimately responsible for cell growth, migration, and in our case apoptosis. Upon EGFR activation, and internalization within the MDA-MB-468 cell line, we speculate that endosomal accumulation of the receptor results in the recruitment of resident proteins, and which are ultimately responsible for initiating the downstream signaling cascade for the induction of apoptosis. Identifying the kinases/proteins that are recruited 
specifically for the induction of apoptosis is an ideal manner of determining how the EGFR is spatially regulated in MDA-MB-468 cells, and in cancer.

In addition to the EGFR, activation of cyclic GMP-dependent protein kinases (PKGs) has been shown to induce dose dependent increases in apoptosis in MDA-MB-468 cells [98]. Data from our MTT assay, utilizing a potent activator of PKG (8-Bromo-cGMP) in MDA-MB-468 cells, indicate that increasing concentrations of the PKG activator result in dose dependent decreases in cell viability (Figure 10). Our findings from this MTT assay complement the findings from the literature, and present us with a kinase candidate with a plausible role in EGFR-mediated apoptosis. Western blot analyses confirm that with the addition of increasing concentrations of EGF ligand, a dose dependent increase in PKG activation is observed, by means of a pVASP(Ser239) antibody. Western blot analyses also confirm that with addition of $3 \mathrm{mM}$ 8-Bromo-cGMP, PKG agonist, activation of PKG is observed, however, no EGFR phosphorylation in observed. This is indicative that PKG is downstream of and activated in a dose dependent manner by the EGFR. Commercially available PKG antagonists, (D)-DT-2 and Rp-8-Br-PET-cGMPs, did not sufficiently inhibit PKG activity within the MDA-MB468 cell line. The lack of inhibition could be due to the fact that the EGFR is directly phosphorylating VASP at the serine 239 residue. It is now clear that siRNA targeting PKG must be employed in order to assess this possibility. Confirming or refuting PKG as an intermediate in EGFR-mediated apoptosis in MDA-MB-468 cells is the next step in defining the regulatory mechanisms of the EGFR in cancer. 
Figure 16.

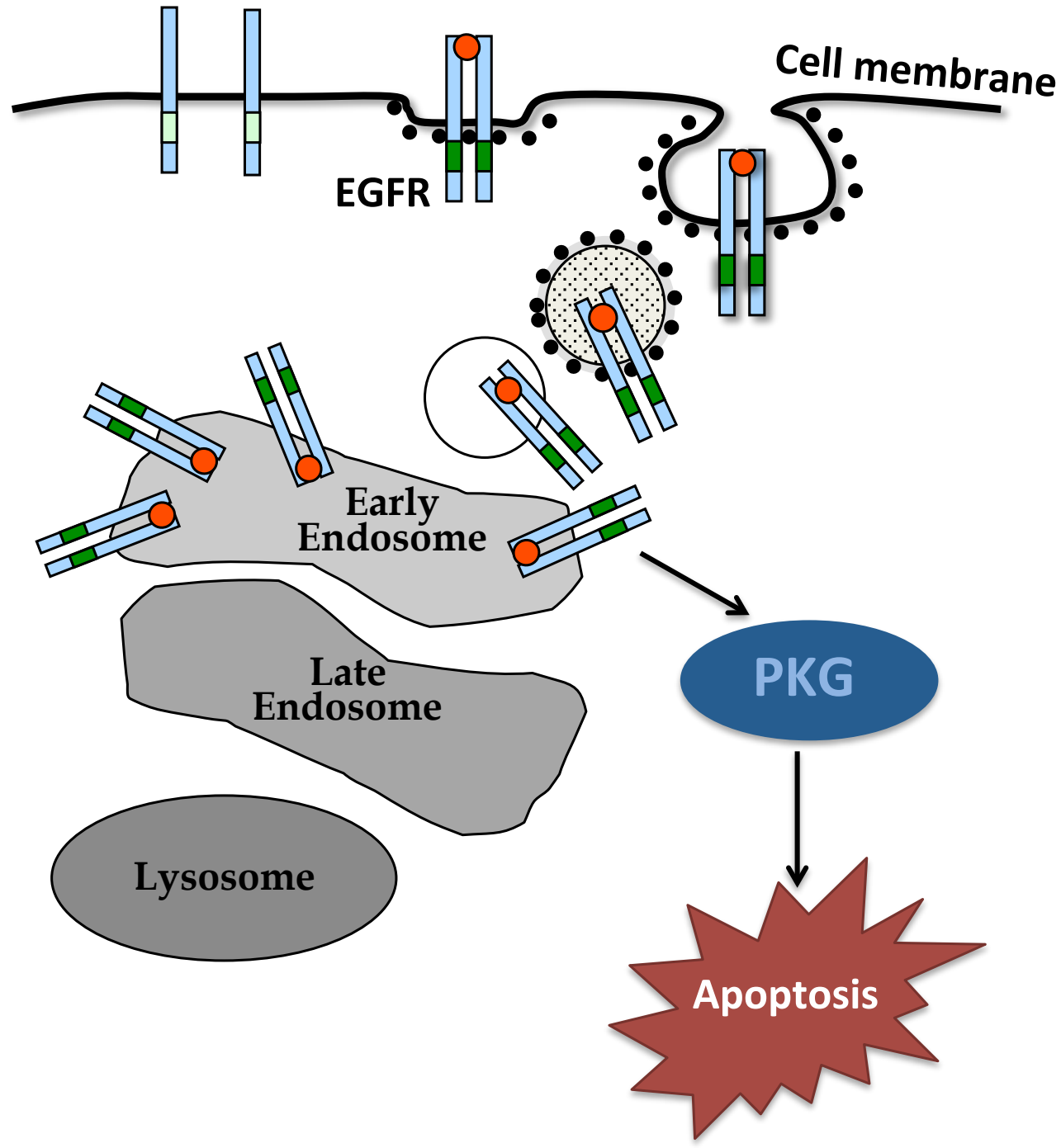

Figure 16. Working model for how EGFR-induced apoptosis occurs in a PKG-mediated manner. The speculation is that PKG is a resident kinase of the early endosome that is recruited to elicit downstream signaling pathways that result in the induction of apoptosis. 
It was also of interest to attempt to find other protein candidates that could potentially be implicated in EGFR-induced apoptosis. Because of this, an EGFReffector screening was conducted. Five proteins, MAPK, AKT, SRC, BAD, and STAT3 were selected due to their differential roles in various, downstream cell signaling pathways. Each of these effectors has been implicated with the EGFR and apoptosis. As previously mentioned, MDA-MB-468 cells undergo cell growth when exposed to low $(1 \mathrm{ng} / \mathrm{mL})$ concentrations of EGF, and apoptosis when exposed to high ( $\leq 10 \mathrm{ng} / \mathrm{mL}$ ) EGF concentrations. The goal was to subject the cells to 2-hour time course experiments with low and high ligand, and then look at signaling within the 5-effector proteins in order to identify and differentiate effectors associated with cell growth (preferential signaling with low ligand), versus those associated with apoptosis (preferential signaling with high ligand). We determined that there was no significant difference in signaling between low and high EGF concentrations among pAKT, pMAPK, pSRC, and pBAD (Figure 7). Therefore, we chose not to pursue these four proteins for subsequent studies.

The MDA-MB-468 cells were also subjected to dose response experiments with EGF ligand, and then subsequent western blot analyses of the dose response experiments. Two protein candidates showed to be dynamically upregulated in an EGFR dose dependent manner: PKG and STAT3 (Figure 9A an Figure 12C, respectively). Data within this thesis do not indicate that STAT3 is constitutively active. Both, dose response and time course data confirm that STAT3 is inactive at low concentrations, and preferentially activated at high concentrations of EGF (Figure 12A and Figure 12B). This suggests that the 
EGFR is activating STAT3 at the high EGF concentrations as an intermediate in the induction of apoptosis. However, it cannot be ruled out that STAT3 is being activated as a compensatory mechanism, in an attempt to rescue the cell from EGFR-mediated apoptosis.

In order to assess the role of STAT3 in EGFR-induced apoptosis, two different STAT3 inhibitors were employed: 5,15-DPP and STATTIC. Although the 5,15-DPP inhibitor was not cytotoxic, it inhibited the EGFR, more than pSTAT3 (Figure 13A). Findings among this thesis also contradict that of the literature, which reports no reduction in pSTAT3(Tyr 705) phosphorylation with $50 \mu \mathrm{M}$ treatment of 5,15-DPP in MDA-MB-468 cells [93]. Similarly to 5,15-DPP, STATTIC also antagonized the EGFR in a dose dependent manner, completely blocking EGFR activation at $100 \mu \mathrm{M}$. Unlike 5,15-DPP, STATTIC was however cytotoxic (Figure 14A). An Alamarblue experiment utilizing STATTIC confirmed a dose dependent decrease in cell viability in response to the STATTIC reagent. STATTIC was also assessed in combination with a fixed concentration (100 $\mathrm{ng} / \mathrm{mL}$ ) of EGF ligand. If STAT3 is being activated as a compensatory mechanism, in favor of cell survival, inhibition of STAT3 with the addition of EGF ligand should potentiate the induction of apoptosis, more than STATTC or EGF alone. The dose response curve of STATTIC + EGF did seem to potentiate a decrease in cell viability, but only at low $(3 \mu \mathrm{M})$ STATTIC concentrations. This is believed to be due to the fact that at high concentrations, STATTIC inhibits activation of the EGFR. Potentiation of cell death of the cells exposed to STATTIC in combination with EGF would not be an expected observation at high 
STATTIC concentrations, because of the minimal EGFR activity occurring. In order to accurately assess the role of STAT3 in EGFR-induced apoptosis, siRNA targeting STAT3 must be employed. Through use of readily available siRNA, targeting STAT3, it can confidently be confirmed that MDA-MB-468 cells are cable of being subjected to siRNA transfections (Figure 15).

The current model for the role of STAT3 in EGFR-induced apoptosis in MDA-MB-468 cells exists as 2 scenarios (Figure 17). In the left panel; STAT3 is an intermediate in EGFR-induced apoptosis. Similarly to the involution process, STAT3 is upregulated, which causes the post-translational upregulation of cathepsin B. Cathepsin B upregulation leads to lysosomal induction of apoptosis. Conversely, in the right panel, STAT3 is upregulated in an attempt to rescue the cell from EGFR-induced apoptosis. In this portion of the model, STAT3 might be upregulated, specifically at high concentrations as a "rescue mechanism" to avoid the cell undergoing apoptosis. This mechanism inevitably fails, however, which is evidenced by the fact the EGFR-mediated apoptosis occurs in the MDAMB-468 cell line. 
Figure 17.

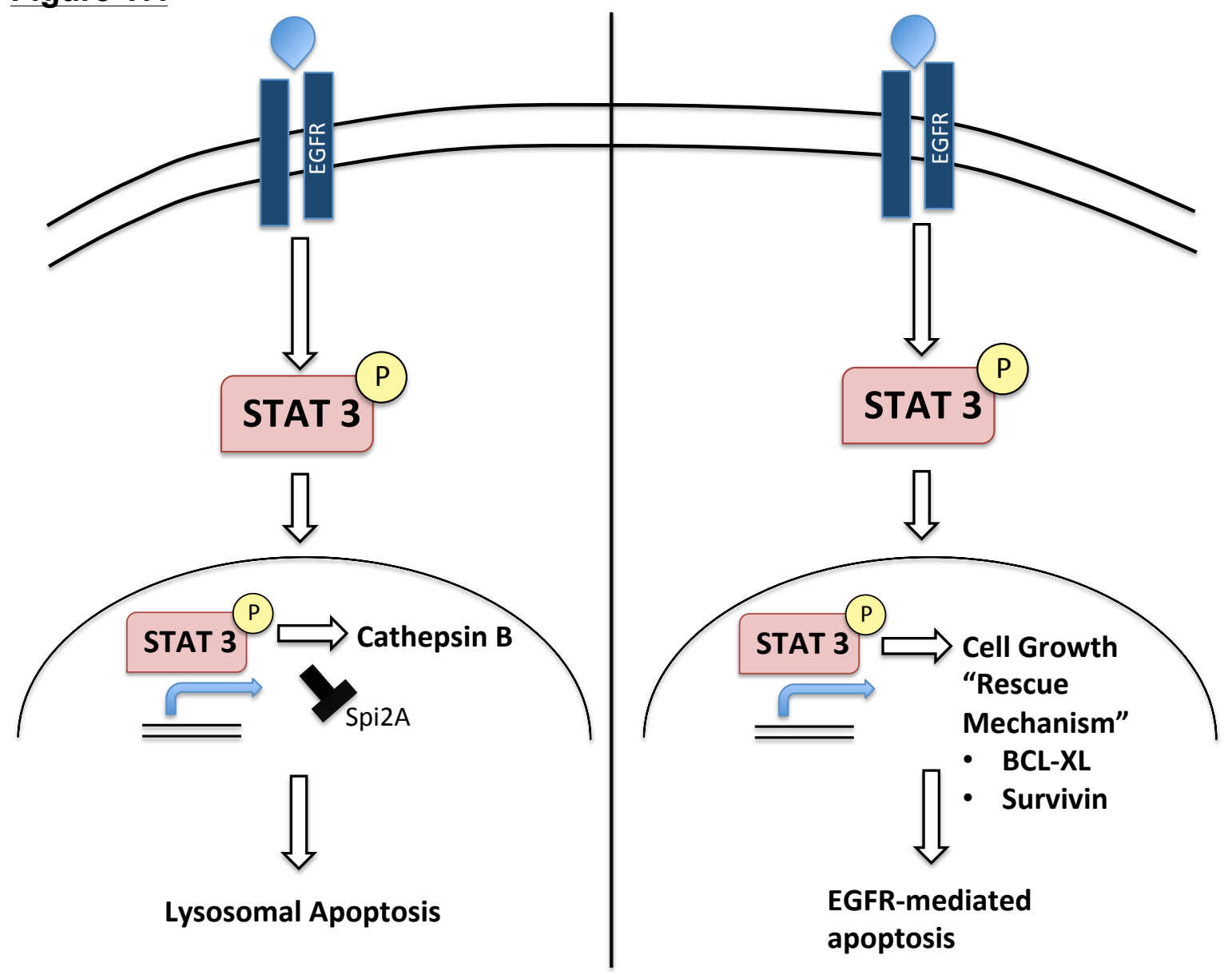

Figure 17. Two models describing the potential roles of STAT3 in EGFRinduced apoptosis in MDA-MB-468 cells. (Adapted from Resemann et al., Molecular and Cellular Endocrinology, 2013). 


\section{SUMMARY AND CONCLUSIONS}

The research conducted within this thesis attempts to identify any ligand specificity in EGFR-mediated apoptosis in MDA-MB-468 breast cancer cells. Cell viability, EGFR-phosphorylation patterns, and cell morphology were all assessed in the MDA-MB-468 cell line upon exposure to EGF, BTC, and TGFA ligands. All of the ligands induce dose dependent decreases in viability, as well as dose dependent increases in EGFR-phosphorylation. Each of the ligands induced rounded cellular morphologies at high concentrations. These findings are indicative that there is no ligand specificity in regard to EGFR-mediated apoptosis within this cell line, and that these cells undergo cell death when exposed to the 3 ligands. This work helped to unveil the roles of endogenous EGFR ligands in receptor trafficking and overall cell viability. However, a different approach had to be employed in order to further understand how the receptor is spatially regulated within our cell line of interest.

Due to time course and dose response experiments, two protein candidates have been identified to potentially play an intermediary role in EGFRinduced apoptosis: PKG and STAT3. Ideally, it is of interest to silence each protein within MDA-MB-468 cells, activate the EGFR, and evaluate their

individual roles in EGFR-mediated apoptosis. Commercially available inhibitors of both proteins have shown not to properly antagonize their functions. 
Therefore, siRNA knockdown of both PKG and STAT3 will be employed for subsequent analyses. Sufficient inactivation of PKG and STAT3 will be verified through immunoblot analyses of total STAT3 and total VASP proteins.

\section{STRENGTHS OF THIS WORK}

The major strength of this work lies within use of MDA-MB-468 cell line. This cell line expressed over one million EGFRs per cell. High receptor expression will elicit high receptor activation, which is ideal for immunoblot analysis and ultimate assessment of EGFR phosphorylation. It is also advantageous that this cell line has a defect in endocytic trafficking, causing the EGFR to accumulate within the early endosome. This allows for a clear, manageable determination of EGFR signaling at the subcellular level. Studying EGFR endocytic trafficking in cells that traffic the receptor efficiently requires the use of pharmacological reagents to trap the receptor at the desired subcellular location. Such use of these reagents are not required due to the natural defect the cells obtain upon EGFR activation and internalization. Overall, this cell line has a natural, tractable response in regard to EGFR activation, allowing for a more manageable model to study receptor trafficking and signaling.

\section{LIMITATIONS AND WEAKNESSES}

Studies conducted at the cellular level have some unavoidable limitations. We are assessing the EGFR:ligand interaction solely in our cell line of interest, and not in vivo. An animal model more accurately recapitulates a human with 
metastatic breast cancer more so than a tissue culture model. An animal or human model is the only manner of determining if exposure to EGFR ligands has any effects other than the intended cancer tissue. A tissue culture experimental model is ideal for preliminary studies, but a major progression within this study and project would be to assess the findings in a more molecularly complex organism. Another limitation within this work lies in the use of pharmacological inhibitors. Data within this thesis confirm that inhibitors can often not antagonize sufficiently (D-DT-2 and Rp-8-Br-PET-cGMPs), or have non-specific, pleiotropic effects on other proteins (5,15-DPP and STATTIC). This is a common finding and hindrance when conducting scientific research. Due to this, we will employ siRNA to specifically target PKG and STAT3 for sufficient inactivation of each protein.

\section{FUTURE DIRECTIONS}

The ultimate goal is continuously to determine receptor:effector relationships that have implications in EGFR-induced apoptosis. Therefore, siRNA knockdown of both PKG and STAT3 will be employed for subsequent analyses of the role of each protein in EGFR-induced apoptosis within the MDAMB-468 cell line. Further advancement of this project will also rely on determining if these 2 proteins are spatially regulated within this cell line. This will require synthesis and employment of EGF ligand, covalently conjugated to polystyrene beads. This molecular tool will allow us to differentiate signaling occurring at the cell membrane versus signaling occurring within the endosomes. 


\section{REFERENCES}

1. Savage, C.R., Jr. and S. Cohen, Epidermal growth factor and a new derivative. Rapid isolation procedures and biological and chemical characterization. J Biol Chem, 1972. 247(23): p. 7609-11.

2. Carpenter, G., L. King, Jr., and S. Cohen, Epidermal growth factor stimulates phosphorylation in membrane preparations in vitro. Nature, 1978. 276(5686): p. 409-10.

3. Cohen, S., R.A. Fava, and S.T. Sawyer, Purification and characterization of epidermal growth factor receptor/protein kinase from normal mouse liver. Proc Natl Acad Sci U S A, 1982. 79(20): p. 6237-41.

4. Lemmon, M.A. and J. Schlessinger, Cell signaling by receptor tyrosine kinases. Cell, 2010. 141(7): p. 1117-34.

5. Lax, l., et al., Localization of a major receptor-binding domain for epidermal growth factor by affinity labeling. Mol Cell Biol, 1988. 8(4): p. 1831-4.

6. Ferguson, K.M., et al., EGF activates its receptor by removing interactions that autoinhibit ectodomain dimerization. Mol Cell, 2003. 11(2): p. 507-17.

7. Ward, C.W., et al., The three dimensional structure of the type I insulin-like growth factor receptor. Mol Pathol, 2001. 54(3): p. 125-32.

8. Yarden, Y. and M.X. Sliwkowski, Untangling the ErbB signalling network. Nat Rev Mol Cell Biol, 2001. 2(2): p. 127-37.

9. Aaronson, S.A., Growth factors and cancer. Science, 1991. 254(5035): p. 1146-53.

10. Ihle, J.N., et al., Signaling through the hematopoietic cytokine receptors. Annu Rev Immunol, 1995. 13: p. 369-98.

11. Kisseleva, T., et al., Signaling through the JAKSSTAT pathway, recent advances and future challenges. Gene, 2002. 285(1-2): p. 1-24.

12. Arteaga, C.L., The epidermal growth factor receptor: from mutant oncogene in nonhuman cancers to therapeutic target in human neoplasia. J Clin Oncol, 2001. 19(18 Suppl): p. 32S-40S.

13. Rowinsky, E.K., The erbB family: targets for therapeutic development against cancer and therapeutic strategies using monoclonal antibodies and tyrosine kinase inhibitors. Annu Rev Med, 2004. 55: p. 433-57.

14. Real, F.X., et al., Expression of epidermal growth factor receptor in human cultured cells and tissues: relationship to cell lineage and stage of differentiation. Cancer Res, 1986. 46(9): p. 4726-31.

15. Reis, R.M., et al., Genetic profile of gliosarcomas. Am J Pathol, 2000. 156(2): p. 425-32. 
16. Gan, H.K., A.N. Cvrljevic, and T.G. Johns, The epidermal growth factor receptor variant III (EGFRvIII): where wild things are altered. FEBS J, 2013. 280(21): p. 5350-70.

17. Libermann, T.A., et al., Amplification, enhanced expression and possible rearrangement of EGF receptor gene in primary human brain tumours of glial origin. Nature, 1985. 313(5998): p. 144-7.

18. Wang, F., et al., Phosphorylated EGFR expression may predict outcome of EGFR-TKIs therapy for the advanced NSCLC patients with wild-type EGFR. J Exp Clin Cancer Res, 2012. 31: p. 65.

19. Sordella, R., et al., Gefitinib-sensitizing EGFR mutations in lung cancer activate anti-apoptotic pathways. Science, 2004. 305(5687): p. 1163-7.

20. Luetteke, N.C., et al., Targeted inactivation of the EGF and amphiregulin genes reveals distinct roles for EGF receptor ligands in mouse mammary gland development. Development, 1999. 126(12): p. 2739-50.

21. Roth, T.F. and K.R. Porter, Yolk Protein Uptake in the Oocyte of the Mosquito Aedes Aegypti. L. J Cell Biol, 1964. 20: p. 313-32.

22. Heuser, J.E. and T.S. Reese, Evidence for recycling of synaptic vesicle membrane during transmitter release at the frog neuromuscular junction. $\mathrm{J}$ Cell Biol, 1973. 57(2): p. 315-44.

23. Pearse, B.M., Coated vesicles from pig brain: purification and biochemical characterization. J Mol Biol, 1975. 97(1): p. 93-8.

24. Sigismund, S., et al., Clathrin-independent endocytosis of ubiquitinated cargos. Proc Natl Acad Sci U S A, 2005. 102(8): p. 2760-5.

25. Lund, K.A., et al., Quantitative analysis of the endocytic system involved in hormone-induced receptor internalization. J Biol Chem, 1990. 265(26): p. 15713-23.

26. Sigismund, S., et al., Threshold-controlled ubiquitination of the EGFR directs receptor fate. EMBO J, 2013. 32(15): p. 2140-57.

27. Presley, J.F., et al., Bafilomycin A1 treatment retards transferrin receptor recycling more than bulk membrane recycling. J Biol Chem, 1997.

272(21): p. 13929-36.

28. Perret, E., et al., Evolving endosomes: how many varieties and why? Curr Opin Cell Biol, 2005. 17(4): p. 423-34.

29. Ang, A.L., et al., Recycling endosomes can serve as intermediates during transport from the Golgi to the plasma membrane of MDCK cells. J Cell Biol, 2004. 167(3): p. 531-43.

30. Murray, R.Z., et al., A role for the phagosome in cytokine secretion. Science, 2005. 310(5753): p. 1492-5.

31. Sigismund, S., et al., Clathrin-mediated internalization is essential for sustained EGFR signaling but dispensable for degradation. Dev Cell, 2008. 15(2): p. 209-19.

32. Ceresa, B.P., Spatial regulation of epidermal growth factor receptor signaling by endocytosis. Int J Mol Sci, 2012. 14(1): p. 72-87. 
33. $\mathrm{Xu}, \mathrm{Y} . \mathrm{H}$. , et al., Characterization of epidermal growth factor receptor gene expression in malignant and normal human cell lines. Proc Natl Acad Sci U S A, 1984. 81(23): p. 7308-12.

34. Harris, R.C., E. Chung, and R.J. Coffey, EGF receptor ligands. Exp Cell Res, 2003. 284(1): p. 2-13.

35. Roepstorff, K., et al., Differential effects of EGFR ligands on endocytic sorting of the receptor. Traffic, 2009. 10(8): p. 1115-27.

36. Qu, J., et al., Distribution and epidermal growth factor receptor expression of primordial follicles in human ovarian tissue before and after cryopreservation. Hum Reprod, 2000. 15(2): p. 302-10.

37. Taylor, J.M., S. Cohen, and W.M. Mitchell, Epidermal growth factor: high and low molecular weight forms. Proc Natl Acad Sci U S A, 1970. 67(1): p. 164-71.

38. Thoresen, G.H., et al., Response to transforming growth factor alpha (TGFalpha) and epidermal growth factor (EGF) in hepatocytes: lower EGF receptor affinity of TGFalpha is associated with more sustained activation of p42/p44 mitogen-activated protein kinase and greater efficacy in stimulation of DNA synthesis. J Cell Physiol, 1998. 175(1): p. 10-8.

39. Luetteke, N.C., et al., Characterization of high molecular weight transforming growth factor alpha produced by rat hepatocellular carcinoma cells. Biochemistry, 1988. 27(17): p. 6487-94.

40. Dunbar, A.J. and C. Goddard, Structure-function and biological role of betacellulin. Int J Biochem Cell Biol, 2000. 32(8): p. 805-15.

41. Watanabe, T., et al., Recombinant human betacellulin. Molecular structure, biological activities, and receptor interaction. J Biol Chem, 1994. 269(13): p. 9966-73.

42. Ebner, R. and R. Derynck, Epidermal growth factor and transforming growth factor-alpha: differential intracellular routing and processing of ligand-receptor complexes. Cell Regul, 1991. 2(8): p. 599-612.

43. Fung, C., et al., EGFR tyrosine kinase inhibition induces autophagy in cancer cells. Cancer Biol Ther, 2012. 13(14): p. 1417-24.

44. Armstrong, D.K., et al., Epidermal growth factor-mediated apoptosis of MDA-MB-468 human breast cancer cells. Cancer Res, 1994. 54(20): p. 5280-3.

45. Brabyn, C.J. and L.P. Kleine, EGF causes hyperproliferation and apoptosis in T51B cells: involvement of high and low affinity EGFR binding sites. Cell Signal, 1995. 7(2): p. 139-50.

46. Chin, Y.E., et al., Activation of the STAT signaling pathway can cause expression of caspase 1 and apoptosis. Mol Cell Biol, 1997. 17(9): p. 5328-37.

47. Jacobson, M.D., M. Weil, and M.C. Raff, Programmed cell death in animal development. Cell, 1997. 88(3): p. 347-54.

48. Elmore, S., Apoptosis: a review of programmed cell death. Toxicol Pathol, 2007. 35(4): p. 495-516.

49. Hacker, G., The morphology of apoptosis. Cell Tissue Res, 2000. 301(1): p. 5-17. 
50. Kerr, J.F., A.H. Wyllie, and A.R. Currie, Apoptosis: a basic biological phenomenon with wide-ranging implications in tissue kinetics. $\mathrm{Br} \mathrm{J}$ Cancer, 1972. 26(4): p. 239-57.

51. Crescitelli, R., et al., Distinct RNA profiles in subpopulations of extracellular vesicles: apoptotic bodies, microvesicles and exosomes. J Extracell Vesicles, 2013. 2.

52. Turk, B. and V. Turk, Lysosomes as "suicide bags" in cell death: myth or reality? J Biol Chem, 2009. 284(33): p. 21783-7.

53. Fulda, S. and K.M. Debatin, Apoptosis signaling in tumor therapy. Ann N Y Acad Sci, 2004. 1028: p. 150-6.

54. Hanahan, D. and R.A. Weinberg, The hallmarks of cancer. Cell, 2000. 100(1): p. 57-70.

55. Kabore, A.F., J.B. Johnston, and S.B. Gibson, Changes in the apoptotic and survival signaling in cancer cells and their potential therapeutic implications. Curr Cancer Drug Targets, 2004. 4(2): p. 147-63.

56. Ikehara, N., et al., BRAF mutation associated with dysregulation of apoptosis in human colorectal neoplasms. Int J Cancer, 2005. 115(6): p. 943-50.

57. Reed, J.C., Apoptosis-targeted therapies for cancer. Cancer Cell, 2003. 3(1): p. 17-22.

58. DiBona, D.R. and W.J. Powell, Jr., Quantitative correlation between cell swelling and necrosis in myocardial ischemia in dogs. Circ Res, 1980. 47(5): p. 653-65.

59. Levin, S., et al., The nomenclature of cell death: recommendations of an ad hoc Committee of the Society of Toxicologic Pathologists. Toxicol Pathol, 1999. 27(4): p. 484-90.

60. Zeiss, C.J., The apoptosis-necrosis continuum: insights from genetically altered mice. Vet Pathol, 2003. 40(5): p. 481-95.

61. Hengartner, M.O., The biochemistry of apoptosis. Nature, 2000. 407(6805): p. 770-6.

62. Logue, S.E. and S.J. Martin, Caspase activation cascades in apoptosis. Biochem Soc Trans, 2008. 36(Pt 1): p. 1-9.

63. Slee, E.A., C. Adrain, and S.J. Martin, Executioner caspase-3, -6, and -7 perform distinct, non-redundant roles during the demolition phase of apoptosis. J Biol Chem, 2001. 276(10): p. 7320-6.

64. Cohen, G.M., Caspases: the executioners of apoptosis. Biochem J, 1997. 326 ( Pt 1): p. 1-16.

65. Grutter, M.G., Caspases: key players in programmed cell death. Curr Opin Struct Biol, 2000. 10(6): p. 649-55.

66. Locksley, R.M., N. Killeen, and M.J. Lenardo, The TNF and TNF receptor superfamilies: integrating mammalian biology. Cell, 2001. 104(4): p. 487501.

67. Ashkenazi, A. and V.M. Dixit, Death receptors: signaling and modulation. Science, 1998. 281(5381): p. 1305-8. 
68. Waring, P. and A. Mullbacher, Cell death induced by the Fas/Fas ligand pathway and its role in pathology. Immunol Cell Biol, 1999. 77(4): p. 3127.

69. Wajant, H., The Fas signaling pathway: more than a paradigm. Science, 2002. 296(5573): p. 1635-6.

70. Kischkel, F.C., et al., Cytotoxicity-dependent APO-1 (Fas/CD95)associated proteins form a death-inducing signaling complex (DISC) with the receptor. EMBO J, 1995. 14(22): p. 5579-88.

71. Adachi, M., et al., Targeted mutation in the Fas gene causes hyperplasia in peripheral lymphoid organs and liver. Nat Genet, 1995. 11(3): p. 294300.

72. Wu, J., et al., Correction of accelerated autoimmune disease by early replacement of the mutated Ipr gene with the normal Fas apoptosis gene in the $T$ cells of transgenic MRL-Ipr/lpr mice. Proc Natl Acad Sci U S A, 1994. 91(6): p. 2344-8.

73. Lawen, A., Apoptosis-an introduction. Bioessays, 2003. 25(9): p. 888-96.

74. Cailleau, R., M. Olive, and Q.V. Cruciger, Long-term human breast carcinoma cell lines of metastatic origin: preliminary characterization. In Vitro, 1978. 14(11): p. 911-5.

75. Filmus, J., et al., MDA-468, a human breast cancer cell line with a high number of epidermal growth factor (EGF) receptors, has an amplified EGF receptor gene and is growth inhibited by EGF. Biochem Biophys Res Commun, 1985. 128(2): p. 898-905.

76. Hyatt, D.C. and B.P. Ceresa, Cellular localization of the activated EGFR determines its effect on cell growth in MDA-MB-468 cells. Exp Cell Res, 2008. 314(18): p. 3415-25.

77. Rush, J.S., et al., Endosomal accumulation of the activated epidermal growth factor receptor (EGFR) induces apoptosis. J Biol Chem, 2012. 287(1): p. 712-22.

78. Corbin, J.D. and S.H. Francis, Cyclic GMP phosphodiesterase-5: target of sildenafil. J Biol Chem, 1999. 274(20): p. 13729-32.

79. Lohmann, S.M., et al., Distinct and specific functions of cGMP-dependent protein kinases. Trends Biochem Sci, 1997. 22(8): p. 307-12.

80. Sausbier, M., et al., Mechanisms of NO/cGMP-dependent vasorelaxation. Circ Res, 2000. 87(9): p. 825-30.

81. Kuo, J.F. and P. Greengard, Cyclic nucleotide-dependent protein kinases. VII. Comparison of various histones as substrates for adenosine 3',5'monophosphate-dependent and guanosine 3',5'-monophosphatedependent protein kinases. Biochim Biophys Acta, 1970. 212(3): p. 43440.

82. Wall, M.E., et al., Mechanisms associated with cGMP binding and activation of cGMP-dependent protein kinase. Proc Natl Acad Sci U S A, 2003. 100(5): p. 2380-5.

83. Brown, N.R., et al., The structural basis for specificity of substrate and recruitment peptides for cyclin-dependent kinases. Nat Cell Biol, 1999. 1(7): p. 438-43. 
84. Fraser, M., et al., Regulation of p53 and suppression of apoptosis by the soluble guanylyl cyclase/cGMP pathway in human ovarian cancer cells. Oncogene, 2006. 25(15): p. 2203-12.

85. Leung, E.L., et al., Protein kinase $G$ type lalpha activity in human ovarian cancer cells significantly contributes to enhanced Src activation and DNA synthesis/cell proliferation. Mol Cancer Res, 2010. 8(4): p. 578-91.

86. Wong, J.C. and R.R. Fiscus, Protein kinase $G$ activity prevents pathological-level nitric oxide-induced apoptosis and promotes DNA synthesis/cell proliferation in vascular smooth muscle cells. Cardiovasc Pathol, 2010. 19(6): p. e221-31.

87. Fallahian, F., F. Karami-Tehrani, and S. Salami, Induction of apoptosis by type Ibeta protein kinase $G$ in the human breast cancer cell lines MCF-7 and MDA-MB-468. Cell Biochem Funct, 2012. 30(3): p. 183-90.

88. Darnell, J.E., Jr., STATS and gene regulation. Science, 1997. 277(5332): p. $1630-5$.

89. Turkson, J., STAT proteins as novel targets for cancer drug discovery. Expert Opin Ther Targets, 2004. 8(5): p. 409-22.

90. Yue, P. and J. Turkson, Targeting STAT3 in cancer: how successful are we? Expert Opin Investig Drugs, 2009. 18(1): p. 45-56.

91. $\mathrm{Yu}, \mathrm{H}$. and R. Jove, The STATs of cancer--new molecular targets come of age. Nat Rev Cancer, 2004. 4(2): p. 97-105.

92. Garcia, R., et al., Constitutive activation of Stat3 by the Src and JAK tyrosine kinases participates in growth regulation of human breast carcinoma cells. Oncogene, 2001. 20(20): p. 2499-513.

93. Uehara, Y., et al., Novel high-throughput screening system for identifying STAT3-SH2 antagonists. Biochem Biophys Res Commun, 2009. 380(3): p. 627-31.

94. Minami, M., et al., STAT3 activation is a critical step in gp130-mediated terminal differentiation and growth arrest of a myeloid cell line. Proc Natl Acad Sci U S A, 1996. 93(9): p. 3963-6.

95. Watson, C.J. and W.T. Khaled, Mammary development in the embryo and adult: a journey of morphogenesis and commitment. Development, 2008. 135(6): p. 995-1003.

96. Watson, C.J. and K. Neoh, The Stat family of transcription factors have diverse roles in mammary gland development. Semin Cell Dev Biol, 2008. 19(4): p. 401-6.

97. Resemann, H.K., C.J. Watson, and B. Lloyd-Lewis, The Stat3 paradox: a killer and an oncogene. Mol Cell Endocrinol, 2014. 382(1): p. 603-11.

98. Fallahian, F., et al., Cyclic GMP induced apoptosis via protein kinase $G$ in oestrogen receptor-positive and -negative breast cancer cell lines. FEBS J, 2011. 278(18): p. 3360-9. 


\title{
CURRICULUM VITAE
}

\section{Nicole M. Jackson}

\section{CONTACT INFORMATION:}

\author{
Address: \\ University of Louisville \\ Department of Pharmacology and Toxicology \\ 505 S. Hancock Street \\ $352 \mathrm{~F}$ \\ Louisville, KY 40202
}

(502) 852-2115

NMJack05@louisville.edu

\section{EDUCATION:}

2012- present M.S. and Ph.D. in Pharmacology and Toxicology University of Louisville, Louisville, KY

May 2012

B.A. Summa Cum Laude in Chemistry Cheyney University of Pennsylvania, Cheyney, PA

\section{DISSERTATION:}

Graduate Student, University of Louisville, Department of Pharmacology and Toxicology, Louisville, KY

Mentor: Dr. Brian Ceresa

October 2012 - present

- My dissertation project entails identifying downstream effector proteins with implications in the induction of apoptosis in metastatic breast cancer cells that hyper-express the Epidermal Growth Factor Receptor (EGFR). Through my studies in this laboratory, I have become familiar with cell culture, western blot analysis and SDSPAGE, and various methods of inducing and analyzing apoptosis. 


\section{RESEARCH EXPERIENCE:}

Intern, University of Louisville, Department of Pharmacology and Toxicology, Louisville, KY

Mentor: Dr. David Hein

May 2012 - August 2012

- Conducted research on N-Acetyltransferase I (NAT1), a phase II metabolizing enzyme with altered activity in cancer. I prepared several natural compounds in combination with a small molecule inhibitor of NAT1 in order to increase the inhibitor's potency of NAT1 in metastatic breast cancer cell lines. Skills acquired through this internship include use of HPLC and general cell culture.

Undergraduate Research Assistant, West Chester University Equine Toxicology and Research Laboratory, West Chester, PA

Mentor: Dr. Cornelius Uboh

June 2011 - May 2012

- Assisted in laboratory research involving anabolic steroids and performance enhancement supplements. I also assisted in blood plasma analysis and confirmation of anabolic steroids in horses that participated in competitive racing within the state of Pennsylvania. Through this assistantship, I became familiar with various toxicological extraction methods of blood plasma for High Performance Liquid Chromatography- Mass Spectrometry, (HPLC-MS) as well as general use of HPLC-MS.

Intern, Children's Hospital of Philadelphia, Department of General Surgery, Philadelphia, PA

Mentor: Dr. Timothy Brazelton

May 2010 - August 2010

- Assisted on a drug discovery project entailing a hypertensive drug, Losartan, which was suspected of inducing myofiber regeneration in a mouse model for Duchenne Muscular Dystrophy. Through this internship, I became familiar with frozen sectioning using a cryostat, tissue staining, general histology, and use of confocal microscopy. I also assisted the lab research team with in vivo GFP-labeled bone marrow injections into mice for sickle cell disease research.

\section{ACADEMIC AND PROFESSIONAL HONORS:}

- Cheyney University Student of the Month (February 2009)

- Cheyney University Academic Excellence (Fall 2008 - Spring 2012)

- Cheyney University NSF-BEAMS Scholarship recipient (2008 - 2010)

- Cheyney University Keystone Scholarship recipient (2010 - 2012) 
- Cheyney University Provost's Award for Leadership Award recipient (April 2012)

- University of Louisville IPIBS Fellowship recipient (August 2012- July 2014)

- Southern Regional Education Board (SREB) Doctoral Scholar Fellowship recipient (August 2014-present)

- 500 Euro Travel Award recipient to the $7^{\text {th }}$ International Conference on cGMP (June 2015)

- Third place award recipient at The 2015 Midwest Membrane Trafficking and Signaling Symposium (July 2015)

\section{ACTIVITIES:}

- Member and secretary of Black Biomedical Graduate Student Organization (BBGSO) at the University of Louisville (2012 - present)

- Member of Beta Kappa Chi Scientific Honor Society (2011 - 2012)

- Member of the Keystone Honor Society (2010-2012)

\section{CONFERENCES:}

Presenter, $7^{\text {th }}$ International Conference on cGMP, Trier, Germany June 2015

- A scientific conference held for Ph.D. students who study cyclic-GMP protein interactions.

Conferee, Thurgood Marshall Leadership Conference, New York, NY October 2011

- A selective conference held in order to aid students of color from participating Historically Black Colleges and Universities in their interpersonal development of leadership skills.

Conferee, Eastern Analytical Symposium and Exposition Conference, Somerset, NJ

November 2010

- A conference held for youth with particular interests in chemistry and chemical instrumentation.

Conferee, Women of Color STEM Conference, Dallas, TX October 2010

- A networking conference held for minority women pursuing advanced careers in science, technology, engineering, and mathematics. 


\section{ABSTRACTS:}

1. Jackson, N., Leggett, C., Doll. M., States. C., and Hein., D. 2012. Inhibition of Human Arylamine N-Acetyltransferase I using Curcumin and Resveratrol Increases the Potency of Small Inhibitor Compound 10. Abstract for poster presentation, Research!Louisville, Louisville, KY.

2. Jackson, N. and Ceresa, B. 2013. Endogenous EGFR Ligands as Mediators of Apoptosis in Metastatic Breast Cancer Cells. Abstract for poster presentation, Research!Louisville, Louisville, KY.

3. Jackson, N. Ceresa B. 2015. Cyclic GMP Dependent Protein Kinase (PKG) as a mediator of EGFR-induced Apoptosis. Abstract for poster presentation. $7^{\text {th }}$ International Conference on cGMP, Trier, Germany.

4. Jackson, N. Ceresa B. 2015. Cyclic GMP Dependent Protein Kinase (PKG) as a mediator of EGFR-induced Apoptosis. Abstract for poster presentation, The 2015 Midwest Membrane Trafficking and Signaling Symposium, Louisville, KY. 